This document is the Accepted Manuscript version of a Published Work that appeared in final form in Nano Letters, copyright (c) American Chemical Society after peer review and technical editing by the publisher. To access the final edited and published work see:

https://dx.doi.org/10.1021/acs. nanolett. 8b00612. 


\section{Reduction of Thermal Conductivity in Nanowires by Combined Engineering of Crystal Phase and Isotope Disorder}

Samik Mukherjee, Uri Givan, Stephan Senz, María de la Mata, Jordi Arbiol, and Oussama Moutanabbir

Nano Lett., Just Accepted Manuscript • DOI: 10.1021/acs.nanolett.8b00612 • Publication Date (Web): 25 Apr 2018

Downloaded from http://pubs.acs.org on April 26, 2018

\section{Just Accepted}

"Just Accepted" manuscripts have been peer-reviewed and accepted for publication. They are posted online prior to technical editing, formatting for publication and author proofing. The American Chemical Society provides "Just Accepted" as a service to the research community to expedite the dissemination of scientific material as soon as possible after acceptance. "Just Accepted" manuscripts appear in full in PDF format accompanied by an HTML abstract. "Just Accepted" manuscripts have been fully peer reviewed, but should not be considered the official version of record. They are citable by the Digital Object Identifier (DOI®). "Just Accepted" is an optional service offered to authors. Therefore, the "Just Accepted" Web site may not include all articles that will be published in the journal. After a manuscript is technically edited and formatted, it will be removed from the "Just Accepted" Web site and published as an ASAP article. Note that technical editing may introduce minor changes to the manuscript text and/or graphics which could affect content, and all legal disclaimers and ethical guidelines that apply to the journal pertain. ACS cannot be held responsible for errors or consequences arising from the use of information contained in these "Just Accepted" manuscripts. 


\title{
Reduction of Thermal Conductivity in Nanowires by Combined Engineering of Crystal Phase and Isotope Disorder
}

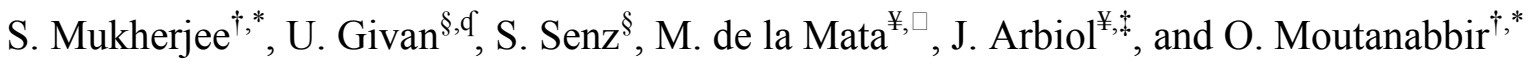 \\ ${ }^{\dagger}$ Department of Engineering Physics, École Polytechnique de Montréal, C. P. 6079, Succ. \\ Centre-Ville, Montreal, Québec H3C 3A7, Canada \\ ${ }^{\S}$ Max Planck Institute of Microstructure Physics, Weinberg 2, D 06120 Halle (Saale), Germany \\ ¥ Catalan Institute of Nanoscience and Nanotechnology (ICN2), CSIC and BIST, Campus UAB, \\ Bellaterra, 08193 Barcelona, Catalonia, Spain \\ $\$$ ICREA, Pg. Lluís Companys 23, 08010 Barcelona, Catalonia, Spain
}

\begin{abstract}
Nanowires are a versatile platform to investigate and harness phonon and thermal transport phenomena in nanoscale systems. With this perspective, we demonstrate herein the use of crystal phase and mass disorder as effective degrees of freedom to manipulate the behavior of phonons and control the flow of local heat in silicon nanowires. The investigated nanowires consist of isotopically pure and isotopically mixed nanowires bearing either a pure diamond cubic or a cubic-rhombohedral polytypic crystal phase. The nanowires with tailor-made isotopic compositions were grown using isotopically enriched silane precursors ${ }^{28} \mathrm{SiH}_{4},{ }^{29} \mathrm{SiH}_{4}$, and ${ }^{30} \mathrm{SiH}_{4}$ with purities better than $99.9 \%$. The analysis of polytypic nanowires revealed ordered and modulated inclusions of lamellar rhombohedral silicon phases towards the center in otherwise diamond-cubic lattice with negligible inter-phase biaxial strain. Raman nanothermometry was employed to investigate the rate at which the local temperature of single suspended nanowires evolves in response to locally generated heat. Our analysis shows that the lattice thermal conductivity in nanowires can be tuned over a broad range by combining the effects of isotope disorder and the nature and degree of polytypism on phonon scattering. We found that the thermal conductivity can be reduced by up to $\sim 40 \%$ relative to that of isotopically pure nanowires, with the lowest value being recorded for the rhombohedral phase in isotopically mixed ${ }^{28} \mathrm{Si}_{x}{ }^{30} \mathrm{Si}_{1-x}$ nanowires with composition close to the highest mass disorder $(x \sim 0.5)$. These results shed new light on the fundamentals of nanoscale thermal transport and lay the groundwork to design innovative phononic devices.
\end{abstract}

Keywords: Thermal Conductivity, stable isotope engineering, polytypic crystal phase, silicon nanowires, phonon engineering, Raman nanothermometry, strain mapping. 
Semiconductor nanowires (NWs) provide a rich playground to explore and elucidate the fundamentals of phonon behavior and thermal transport at the nanoscale. ${ }^{1-3}$ This class of nanomaterials allows the manipulation of thermal conductivity $(\kappa)$ by exploiting confinement related effects and the presence of surface modes, which can alter the phonon dispersion and polarization states, ${ }^{1}$ renormalizing the phonon group velocity and density of states of each branch. Additionally, using the knowledge of the difference in wavelength and mean free path between phonons and electrons, NWs can be designed in a way that the dimension is below the mean free path of phonons but above that of electrons. Consequently, the surface of a NW can be rough to phonons thus reducing their life-time, while remaining smooth to electrons. The possibility of such decoupling of electron transport from the phonons opens up a myriad of opportunities in improving the thermoelectric properties. ${ }^{4-6}$ For instance, silicon (Si) NWs were found to exhibit a diameter-dependent reduction in $\kappa$ compared to the bulk counterpart ${ }^{7}$ and show a significant improvement in the thermoelectric figure of merit ${ }^{8}$. To achieve further enhancement, considerable efforts have been expended to implement methods to design NWbased structures with the aim to manipulate $\kappa$. Among the proposed strategies, one can mention the roughening of NW sidewalls to enhance surface scattering, ${ }^{6}$ alloying, ${ }^{5}$ and periodic chemical alteration $^{9}$, to name a few.

From recent theoretical studies, more methods to tune $\kappa$ in Si NWs have been suggested including surface decoration, ${ }^{10}$ surface faceting, ${ }^{11}$ and thermal rectification in telescopic NWs. ${ }^{12}$ These new NW designs aim at implementing device structures for energy conversion (low $\kappa$ ) or efficient nanoscale heat dissipation (high $\kappa$ ). With this perspective, we report in this letter a novel method to tune $\kappa$ in Si NWs by a combined control of isotopic disorder and crystal phase. Herein, isotope-induced mass disorder is achieved through the manipulation of the isotopic 
content during the NW growth. In addition to this artificial isotope-induced disorder, we also introduce the crystalline phase as an additional degree of freedom to engineer the phonon transport in NWs. Our results demonstrate that, in conjunction with the isotope scattering effect, the phase-specific phonon transport and their scaling behavior can be exploited to control $\kappa$ in $\mathrm{Si}$ NWs, which could be highly relevant to expand the fundamental understanding of a variety of phononic and nano-thermoelectric devices.

The NWs investigated in this work are isotopically controlled grown either with pure diamond cubic phase or polytypic phase. The growth was carried out using ${ }^{28} \mathrm{SiH}_{4},{ }^{29} \mathrm{SiH}_{4}$, and ${ }^{30} \mathrm{SiH}_{4}$ enriched precursors with a purity better than $99.9 \% .{ }^{13}$ These precursors were produced by first enriching $\mathrm{SiF}_{4}$ using Zippe-centrifuge and then converting the obtained ${ }^{28} \mathrm{SiF}_{4},{ }^{29} \mathrm{SiF}_{4}$, and ${ }^{30} \mathrm{SiF}_{4}$ to monosilane following the reaction: $\mathrm{SiF}_{4}+2 \mathrm{CaH}_{2} \rightarrow \mathrm{SiH}_{4}+\mathrm{CaF}_{2}$. Table 1 summarizes the different sets of NWs investigated in this work, their isotopic composition, crystal phase, and the growth conditions. Scanning electron microscope (SEM) images (not shown) revealed that over $50 \%$ of the ${ }^{28} \mathrm{Si}_{\mathrm{x}}{ }^{30} \mathrm{Si}_{1-\mathrm{x}} \mathrm{NWs}$ and ${ }^{30} \mathrm{Si} \mathrm{NWs}$ kinked along the $\langle 121\rangle$ direction from the original $\langle 111\rangle$ direction, close to their base. Additionally, we found, from high-resolution highangle annular dark field scanning transmission electron microscope (HAADF-STEM) and Raman investigations (discussed next), that the kinked NWs possess a polytypic crystal structure with lamellar $\langle 111\rangle$ twins all along the length of the NWs, after the kink. Before delving into the details of the structural properties, it is important to keep in mind that the investigated NWs can be of different isotopic compositions and similar or different phase, or of identical isotopic composition and similar or different crystal phase. As indicated in Table 1, polytypic isotopically mixed ${ }^{28} \mathrm{Si}_{\mathrm{x}}{ }^{30} \mathrm{Si}_{1-\mathrm{x}} \mathrm{NWs}$ and polytypic isotopically pure ${ }^{30} \mathrm{Si} \mathrm{NWs}$ are referred to as $\mathrm{p}$ ${ }^{28} \mathrm{Si}_{\mathrm{x}}{ }^{30} \mathrm{Si}_{1-\mathrm{x}} \mathrm{NWs}$ and $\mathrm{p}-{ }^{30} \mathrm{Si} \mathrm{NWs}$, respectively. NWs made entirely of the diamond cubic phase 
are written from here on without the 'p'. We will also be referring to different crystal phases within a given polytypic NW. For example, the diamond cubic (3C) phase and the rhombohedral (9R) phase within a polytypic isotopically mixed NW shall be referred to as Phase $3 \mathrm{C}-\mathrm{p}$ ${ }^{28} \mathrm{Si}_{\mathrm{x}}{ }^{30} \mathrm{Si}_{1-\mathrm{x}} \mathrm{NWs}$ and ${ }^{\text {Phase }} 9 \mathrm{R}-\mathrm{p}-{ }^{28} \mathrm{Si}_{\mathrm{x}}{ }^{30} \mathrm{Si}_{1-\mathrm{x}} \mathrm{NWs}$, respectively. Other crystal phases within the $\mathrm{p}^{28}{ }^{28 \mathrm{Si}_{\mathrm{x}}}{ }^{30} \mathrm{Si}_{1-\mathrm{x}} \mathrm{NWs}$ and $\mathrm{p}-{ }^{30} \mathrm{Si} \mathrm{NW}$ s shall be referred to accordingly.

Figures 1(a)-(e) show the HAADF-STEM images of a $\mathrm{p}^{28} \mathrm{Si}_{\mathrm{x}}{ }^{30} \mathrm{Si}_{1-\mathrm{x}} \mathrm{NW}$, recorded after the kink and near the tip of the NW. The electron beam in the images were parallel to the [110] Si zone axis. Figure 1(a) exhibits the low magnification image of a NW after the kink. Figures 1(b) exhibits the high-resolution image of the NW thus confirming that the kink direction of the $\mathrm{p}^{28}{ }^{28} \mathrm{i}_{\mathrm{x}}{ }^{30} \mathrm{Si}_{1-\mathrm{x}} \mathrm{NWs}$ to be along the [121] direction. Figure 1(c) shows that the central part of polytypic NWs is composed of lamellar polytypic inclusions bounded by the diamond cubic Si domains. Every twin (marked by white lines) can be considered as a polytypic Si bilayer. The twinned lattice has been clearly marked out in Figure 1(d) by the false yellow color. The power spectrum (FFT) viewed from the [110] direction is shown in the inset. The Bragg's spot marked by the circle was used to generate rotational map (denoted by the false yellow color) in Figure 1(d). The rotation maps were generated using the geometric phase analysis (GPA) software. ${ }^{14,15}$ We have chosen two reflection points separated by $+10^{\circ}$, just to mark the twinned domains. The domains are actually mirror images of each other rotated by $180^{\circ}$. Figure $1(\mathrm{e})$ shows the atomic resolution image recorded at the highest magnification. The stacking sequence of ABACACBCB (each letter denotes a bilayer) is commonly known as the 9R (rhombohedral) polytype in Si. Apart from the 9R polytypic phase, detailed Raman investigations on the ${ }^{2}{ }^{28} \mathrm{Si}_{\mathrm{x}}{ }^{30} \mathrm{Si}_{1-\mathrm{x}} \mathrm{NWs}$ and $\mathrm{p}-{ }^{30} \mathrm{Si}$ NWs revealed the presence of other polytypic phases as well. While in III-V NWs the ordered stacking faults are often found to lie perpendicular to the NW axis in form of a twinned 
axial homojunctions, ${ }^{16,17}$ in the group IV NWs, like Si and Ge NWs, the twin planes are often found to lie along the growth axis of NWs that kink in the $\langle 121\rangle$ direction from the $\langle 111\rangle$ direction at some point during the growth, ${ }^{18-20}$ although there are also few exceptions of twinned axial homojunctions in $\mathrm{Si}^{21,22}$ The underlying mechanism leading to the planar defect generation and growth of kinked polytypic NWs was proposed based on the correlated TEM and Raman analyses on kinked Ge NWs. ${ }^{23}$

Raman scattering spectroscopy is a relatively fast, non-destructive, and high-throughput technique to identify the polytypes and their vibrational behavior. However, before we discuss the identification of the polytypes by using Raman peak position, it is imperative that we estimate the nature and the quantum of interfacial strain that might exist in such polytypic NWs and evaluate the significance of its effect on Raman shift. ${ }^{24,25}$ Figure 2 displays the geometric phase analysis (GPA) of the lattice strain in the $\mathrm{p}^{28} \mathrm{Si}_{\mathrm{x}}{ }^{30} \mathrm{Si}_{1-\mathrm{x}} \mathrm{NW}$. A theoretical discussion on the GPA is given in the supplementary information (SI). The GPA strain maps $\varepsilon_{x x}$ and $\varepsilon_{y y}$ along $x$ and $y$-axis are shown in Figures 2(a) and (b), respectively. The maps were obtained from the HAADF-STEM image shown in the inset of Figure 2(c). The $3 \mathrm{C}$ region marked by the white rectangular box in the HAAD-STEM image (inset, Figure 2(c)) was taken to be the reference for these maps. The color bars for the maps indicate that the green-brown regions correspond to nearly $0 \%$ strain relative to the relaxed reference. The $\varepsilon_{x x}$ GPA maps thus highlight no meaningful variation of the lattice parameter along the radial direction. At a first glimpse, the $\varepsilon_{y y}$ GPA maps seems to be qualitatively similar to the $\varepsilon_{x x}$ maps, but they show some hot-spots (bright-red and yellow regions) especially at the 3C/9R interfaces. The magnitude of the strain along the $x$ - and $y$-axis of the $\mathrm{p}^{28}{ }^{28} \mathrm{i}_{\mathrm{x}}{ }^{30} \mathrm{Si}_{1-\mathrm{x}} \mathrm{NW}$ is shown in Figure 2(c). The average biaxial strain $\left(\left\langle\varepsilon_{\mathrm{xx}}\right\rangle+\left\langle\varepsilon_{\mathrm{yy}}\right\rangle\right) / 2$ shown in the lower panel ( $\varepsilon_{y y}$ strain profile) in Figure 2(c) has the value 
of $0.065 \%$. From the relation $\Delta \omega=\mathrm{b} \Delta \varepsilon_{\mathrm{bi}}$ where ' $\mathrm{b}$ ' is the Raman shift strain coefficient, ${ }^{26}$ the shift in Raman peak position $(\Delta \omega)$ caused by biaxial strain of $\Delta \varepsilon_{\mathrm{bi}}$ is estimated to be $\sim 0.35 \mathrm{~cm}^{-1}$, which is smaller than the spectral resolution of our Raman spectrometer. Therefore, the effect of this small biaxial strain on the Raman peak position and eventually on the phonon transport shall be neglected henceforth.

The details of sample preparation for Raman spectroscopy for polytype identification and heat transport measurements are given in the SI. Representative Raman spectra recorded from p${ }^{28} \mathrm{Si}_{\mathrm{x}}{ }^{30} \mathrm{Si}_{1-\mathrm{x}} \mathrm{NWs}$ and $\mathrm{p}^{30} \mathrm{SiNWs}$ are shown in Figures 3(a)-(b) and Figures 3(c)-(d), respectively. The NWs used in Figure 3 were dispersed on Au-coated natural Si $\left({ }^{\mathrm{Nat}} \mathrm{Si}\right)$ substrates and their Raman spectra were measured at the lowest laser power density of $0.1 \mathrm{~mW} / \mu \mathrm{m}^{2}$ to minimize any laser-induced heating. The spectra were fitted by Voigt function to extract the peak positions and the full width at half maxima (FWHM) intrinsic to the samples under investigation. In Figure 3(a), a stronger peak (at high wavenumber) is located at $511.5 \pm 0.5 \mathrm{~cm}^{-1}$ (red), which is the $\mathrm{F}_{2 \mathrm{~g}}$ mode of ${ }^{\text {Phase }} 3 \mathrm{C}-\mathrm{p}-{ }^{28} \mathrm{Si}_{\mathrm{x}}{ }^{30} \mathrm{Si}_{1-\mathrm{x}}$. A weak satellite peak (at low wavenumbers) can also be observed in Figure 3(a). The position of the satellite peak can be explained by the folding of the Brillouin zone. If the periodicity of the stacking faults within a $\mathrm{NW}$ be $3 \mathrm{a}_{111}$, where $a_{111}$ is the lattice spacing along the [111] direction, then the lattice periodicity gets modulated by the periodicity of the stacking faults. This leads to a folding of the Brillouin zone at $\mathrm{q}=\mathrm{q}_{\max } / 3$, where $\mathrm{q}$ is the phonon wave vector, causing the phonon mode with $\mathrm{q}=$ $2 \mathrm{q}_{\max } / 3$ to fold back into the center of the zone and therefore satisfy the $\mathrm{q} \sim 0$ Raman selection rule. $\mathrm{q}_{\max }$ is the wave vector at the edge of the zone at $\pi / \mathrm{a}_{111}$. This happens for the $9 \mathrm{R}$ polytype in Si. Similarly, if the periodicity of the stacking fault is $2 \mathrm{a}_{111}$, the folding will occur at the middle of the Brillouin zone and the phonon mode at the edge of the zone (at $q=q_{\max }$ ) will 
be folded back to the zone-center and satisfy the Raman selection rule. This happens for the $2 \mathrm{H}$ (hexagonal) polytype in $\mathrm{Si}$. The $9 \mathrm{R}$ and $2 \mathrm{H}$ polytypes are the most common for group IV NWs, although other less common polytypes have also been reported for ${ }^{\mathrm{Nat}} \mathrm{Si} \mathrm{NWs}{ }^{20}$

For a ${ }^{\mathrm{Nat}} \mathrm{Si} \mathrm{NW}$, the wavenumber of the $\mathrm{E}_{\mathrm{g}}\left(\mathrm{E}_{2 \mathrm{~g}}\right)$ modes of the $9 \mathrm{R}(2 \mathrm{H})$ polytypes was reported to be about $496.5 \mathrm{~cm}^{-1}\left(495.5 \mathrm{~cm}^{-1}\right) \cdot{ }^{19,20}$ From the Raman peak position of the $\mathrm{F}_{2 \mathrm{~g}}$ mode in Figure 3(a), the known mass number of ${ }^{28} \mathrm{Si}$ and ${ }^{30} \mathrm{Si}$, and the quasi-harmonic approximation the average isotopic mass of the $\mathrm{p}^{28} \mathrm{Si}_{\mathrm{x}}{ }^{30} \mathrm{Si}_{1-\mathrm{x}} \mathrm{NWs}$ can be estimated to be $\overline{\mathrm{m}}_{\mathrm{p} \text {-IsoMix }}=29.015 \mathrm{amu}$. This also gives the fractional isotopic composition of ${ }^{28} \mathrm{Si}$ in $\mathrm{p}$ ${ }^{28} \mathrm{Si}_{\mathrm{x}}{ }^{30} \mathrm{Si}_{1-\mathrm{x}} \mathrm{NW}$ to be $0.42 \pm 0.03$. Note that the same isotopic composition was measured for ${ }^{28} \mathrm{Si}_{\mathrm{x}}{ }^{30} \mathrm{Si}_{1-\mathrm{x}} \mathrm{NWs}$ using both Raman scattering and atom probe tomography. Since the phonon energies follow the inverse mass dependence under the quasi-harmonic approximation, which is valid around room temperature, the position of the $E_{g}\left(E_{2 g}\right)$ modes of the $9 R(2 H)$ polytypes in the $\mathrm{p}^{-28} \mathrm{Si}_{\mathrm{x}}{ }^{30} \mathrm{Si}_{1-\mathrm{x}} \mathrm{NWs}$ can be estimated to be at $487.8 \mathrm{~cm}^{-1}\left(486.5 \mathrm{~cm}^{-1}\right)$. The calculated value of the $E_{g}$ mode of the $9 R$ polytype agrees well with the experimental data presented in the Figure 3(a) (fitted with blue line). An overwhelming majority of all the $\mathrm{p}^{28} \mathrm{Si}_{\mathrm{x}}{ }^{30} \mathrm{Si}_{1-\mathrm{x}} \mathrm{NWs}$ we investigated using Raman spectroscopy (between 25-30 isolated NWs) possessed the 9R polytypes while only a few showed the signatures of other polytypes, like that shown in Figure 3(b) (left: $2 \mathrm{H}$ polytype and right: $9 \mathrm{R}+2 \mathrm{H}$ polytypes). One surprising aspect of the Raman spectra of both the $9 \mathrm{R}$ and $2 \mathrm{H}$ polytype is that we do not observe the $\mathrm{A}_{1 \mathrm{~g}}$ mode. For ${ }^{\mathrm{Nat}} \mathrm{Si} \mathrm{NWs}$, the $\mathrm{A}_{1 \mathrm{~g}}$ mode is detected at $\sim 517 \mathrm{~cm}^{-1}$ for the 9R polytype and at $\sim 507 \mathrm{~cm}^{-1}$ for the $2 \mathrm{H}$ polytype. ${ }^{19,20}$ As we shall address later, the appearance of the $\mathrm{A}_{1 \mathrm{~g}}$ mode in the Raman spectra for the NWs 
under investigation depends on the fractional volume of the polytypic crystal phase within the NW.

Figure 3(c) shows the Raman spectra recorded for a $\mathrm{p}^{30} \mathrm{Si} \mathrm{NW}$. The high wavenumber peak at $504.5 \pm 0.5 \mathrm{~cm}^{-1}$ (fitted with red line) is assigned to the $\mathrm{F}_{2 \mathrm{~g}}$ mode of the Phase $3 \mathrm{C}$-p${ }^{30} \mathrm{Si}$ NWs. Analogously, the quasi-harmonic approximation allows us to determine the energy of the $E_{g}\left(E_{2 g}\right)$ mode for the $9 R(2 H)$ polytypes in $p-{ }^{30}$ Si NWs. The low wavenumber satellite peak in Figure 3(c), located at $480.2 \pm 0.5 \mathrm{~cm}^{-1}$ (fitted with blue line) can be assigned to the $\mathrm{E}_{\mathrm{g}}$ mode of ${ }^{\text {Phase } 9 R-p-~}{ }^{30} \mathrm{Si}$ NW. Just like the $\mathrm{p}^{28} \mathrm{Si}_{\mathrm{x}}{ }^{30} \mathrm{Si}_{1-\mathrm{x}} \mathrm{NWs}$, we do not see the $\mathrm{A}_{1 \mathrm{~g}}$ mode of

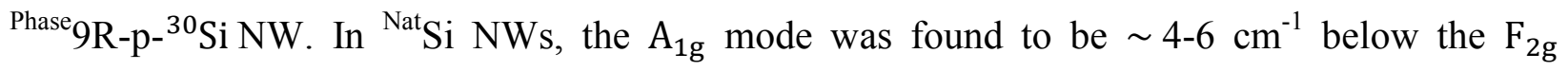
mode. ${ }^{19}$ As a result of the overlap of the $F_{2 g}$ and the $A_{1 g}$, the high wavenumber peak was found to be significantly broad (about 6-8 $\mathrm{cm}^{-1}$ broader compared to the FWHM of either the $\mathrm{F}_{2 \mathrm{~g}}$ or the $\mathrm{A}_{1 \mathrm{~g}}$ mode) and centered at $\sim 518 \mathrm{~cm}^{-1}$ (red-shifted by $\sim 2-3 \mathrm{~cm}^{-1}$ compared to the $\mathrm{F}_{2 \mathrm{~g}}$ mode of 3C- ${ }^{\mathrm{Nat}} \mathrm{Si}$ at $\sim 520.8 \mathrm{~cm}^{-1}$ ). To ascertain if the $\mathrm{A}_{1 \mathrm{~g}}$ mode has any contribution to the high wavenumber peak in Figure 3(c), we overlapped it with spectra of a pure 3C crystal phase ${ }^{30} \mathrm{Si} \mathrm{NW}$ and compared the relative peak position and FWHM. From the overlap, highlighted in Figure S1 and associated discussion, any contribution of the $A_{1 g}$ mode of the $9 R$ phase to the high wavenumber peak of the $\mathrm{p}-{ }^{28} \mathrm{Si}_{\mathrm{x}}{ }^{30} \mathrm{Si}_{1-\mathrm{x}} \mathrm{NWs}$ is subsequently ruled out.

As shown in Figure 3(d)-left, the Raman spectrum from some $\mathrm{p}^{30} \mathrm{Si} \mathrm{NW}$ s showed the $\mathrm{E}_{\mathrm{g}}$ peak from the ${ }^{\text {Phase }} 9 \mathrm{R}$ to be equal in intensity to the $\mathrm{F}_{2 \mathrm{~g}}$ mode from the ${ }^{\mathrm{Phase}} 3 \mathrm{C}$. Among other parameters like the scattering cross-sections, a key factor which affects the Raman intensity is the excitation volume or the volume within a material that gives rise to the Raman signal. The 
spectrum displayed in Figure 3(d)-left thus indicates that the volume of the ${ }^{\text {Phase }} 9 \mathrm{R}$ within the NW is higher than that within the NW shown in Figure 3(c). This behavior gives us a unique opportunity to extend the realm of parameters from the isotopic composition and crystal phase to the fractional volume of the polytypic phase within a NW. For convenience, we shall be denoting the first type of $\mathrm{p}^{30}{ }^{30} \mathrm{Si} W \mathrm{~N}$ with $\mathrm{V}_{3 \mathrm{C}}>\mathrm{V}_{9 \mathrm{R}}$ as $\mathrm{p}-{ }^{30} \mathrm{Si} \mathrm{NW}$ Type1 and the second type with $\mathrm{V}_{3 \mathrm{C}} \approx$ $\mathrm{V}_{9 \mathrm{R}}$ as $\mathrm{p}-{ }^{30} \mathrm{Si} \mathrm{NW}$ Type2. Now, we can see that the high wavenumber peak in $\mathrm{p}-{ }^{30} \mathrm{Si} \mathrm{NW}_{\text {Type2 } 2}$ is slightly red-shifted (by $\sim 0.8 \mathrm{~cm}^{-1}$ ) and broader (by $\sim 2.8 \mathrm{~cm}^{-1}$ ) compared to what the $\mathrm{F}_{2 \mathrm{~g}}$ mode alone could give. The cumulative profile (orange line) is significantly improved if we fit the high wavenumber peak with two Voigt lines: a strong $\mathrm{F}_{2 \mathrm{~g}}$ mode of the ${ }^{\text {Phase }} 3 \mathrm{C}$ (red line) and a weak $A_{1 g}$ mode of the Phase $9 R$ (green). The integrated intensity of the green curve $\left(A_{1 g}\right)$ is smaller by more than an order of magnitude compared to the red curve $\left(\mathrm{F}_{2 \mathrm{~g}}\right)$. Interestingly, as shown in Figure 3(d)-right, we found a few $\mathrm{p}^{30}{ }^{30} \mathrm{Si}$ NWs where the $\mathrm{E}_{\mathrm{g}}$ peak from the ${ }^{\text {Phase }} 9 \mathrm{R}$ is stronger than the high wavenumber peak which is now significantly broader (by $\sim 7.5 \mathrm{~cm}^{-1}$ ) and redshifted (by $\sim 2.0 \mathrm{~cm}^{-1}$ ) compared to what the $\mathrm{F}_{2 \mathrm{~g}}$ mode alone could give. Clearly, two Voigt line profiles were required for fitting the high wavenumber peak in order to deconvolute the overlap of the $F_{2 g}$ (fitted with red line) and $A_{1 g}$ (fitted with green line) modes. We will be calling such NWs with $V_{9 R}>V_{3 C}$ as $p-{ }^{30} \mathrm{Si} \mathrm{NW}$ Type3. The relative abundance of the $\mathrm{p}-{ }^{30} \mathrm{Si}$ NWs follows the

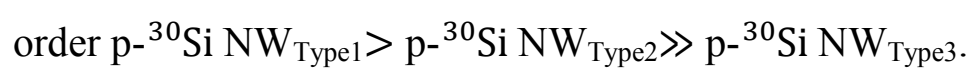

Raman nanothermometry was subsequently employed to measure the heat transport within individual NWs. A schematic illustration of the principles of the nanothermometric measurements is outlined in the SI. To conduct these measurements, it is important to eliminate any substrate from underneath the NWs which might affect the flow of heat. Consequently, NWs 
were suspended on $\mathrm{Au}$ grids prior to nanothermometry analysis (details on Raman sample preparation section in SI). For each NW set, the raw data collected from about 10-15 individual NWs first went through baseline correction, normalization, and then fitted with Voigt line profile(s) to extract the peak position and the FWHM. It is important to state that the comparison of heat transport will be presented for the ${ }^{29} \mathrm{Si} W \mathrm{~N},{ }^{28} \mathrm{Si}_{\mathrm{x}}{ }^{30} \mathrm{Si}_{1-\mathrm{x}} \mathrm{NWs}$ (pure $3 \mathrm{C}$ crystal phases) and for polytypic ${ }^{-30}{ }^{30} \mathrm{NW}_{\text {Type1 }}, \mathrm{p}^{30} \mathrm{Si} \mathrm{NW}_{\text {Type2}}$, and the $\mathrm{p}-{ }^{28} \mathrm{Si}_{\mathrm{x}}{ }^{30} \mathrm{Si}_{1-\mathrm{x}} \mathrm{NWs}$ with $9 \mathrm{R}$ polytypes. For the least abundant polytypes $\left(\mathrm{p}^{3}{ }^{30} \mathrm{Si} \mathrm{NW}_{\mathrm{Type} 3}, \mathrm{p}^{-28} \mathrm{Si}_{\mathrm{x}}{ }^{30} \mathrm{Si}_{1-\mathrm{x}} \mathrm{NWs}\right.$ with $2 \mathrm{H}$ and $9 \mathrm{R}+2 \mathrm{H}$ polytypes), we did not find enough NWs to present a statistically significant data set. The evolution of the Raman peak position of individual NWs was first extracted as the laser power density was increased in steps from 0.1 to $1.5 \mathrm{~mW} / \mu \mathrm{m}^{2}$. The shift in the Raman peak position was used to extract the local temperature of individual NWs. The Raman peak position of a NW, $\Omega(\mathrm{T})$, at a temperature $\mathrm{T}$, is given by $\Omega(\mathrm{T})=\omega_{0}+\Pi(\mathrm{T})$, where $\omega_{0}$ is the bare harmonic phonon frequency and $\Pi(\mathrm{T})$ is the shift of peak position at $\mathrm{T}$, which considering only the thirdorder phonon interaction is given by: ${ }^{27}$

$$
\Pi(\mathrm{T})=\mathrm{C}^{\prime}\left[1+\frac{2}{\mathrm{e}^{\hbar \omega_{0} / 2 \mathrm{k}_{\mathrm{B}} \mathrm{T}}-1}\right]
$$

where $C^{\prime}$ is an arbitrary constant. To ensure an accurate analysis, we have performed control experiments on suspended ${ }^{29} \mathrm{Si} W \mathrm{NW}$ and ${ }^{28} \mathrm{Si}_{\mathrm{x}}{ }^{30} \mathrm{Si}_{1-\mathrm{x}} \mathrm{NWs}$ prepared under identical conditions. $\mathrm{C}^{\prime}$ was evaluated knowing that the NW temperature equals the ambient temperature $(300 \mathrm{~K})$ at the lowest incident laser power density. ${ }^{13}$ The evolution of Raman peak position of five different ${ }^{29} \mathrm{Si}$ NWs and five different ${ }^{28} \mathrm{Si}_{\mathrm{x}}{ }^{30} \mathrm{Si}_{1-\mathrm{x}} \mathrm{NWs}$ as a function of the laser power density is shown in Figures S3, while the average temperatures of 15 different NWs of each type are given in 
Figure S4(a). The difference in the Raman peak position and the corresponding local temperature of NWs suspended differently atop the Au grid is shown in Figure S5 and S6, and is discussed in section $\mathrm{E}$ of the SI. Note that the method to estimate the bare harmonic phonon frequency ' $\omega_{0}$ ' for all NWs and crystal phases is Figure S7 and its associated discussion in section F of the SI. Although the rise in temperature is non-linear over the entire incident power range, for the low power regime $\left(0.1-0.75 \mathrm{~mW} / \mu \mathrm{m}^{2}\right)$ the evolution of temperature is linear, as highlighted in Figure 4(a). The effect of suspending the NWs is prominent, especially around the highest laser power densities $\left(1.0\right.$ and $\left.1.50 \mathrm{~mW} / \mu \mathrm{m}^{2}\right)$. For instance, when ${ }^{28} \mathrm{Si}_{\mathrm{x}}{ }^{30} \mathrm{Si}_{1-\mathrm{x}} \mathrm{NWs}$ are dispersed on $\mathrm{Au}$ substrate, reaching an average temperature of $390 \mathrm{~K}$ requires an incident power density of about $8.0 \mathrm{~mW} / \mu \mathrm{m}^{2} \cdot{ }^{13}$ Herein, a similar temperature is observed at a much lower power density of 1.50 $\mathrm{mW} / \mu \mathrm{m}^{2}$. The ratio of $\kappa$ around the room temperature for the two sets of NWs was calculated from the slopes of the linear regime in Figure 4(a). The $\kappa_{29-S i} / \kappa_{\text {Iso-Mix }}$ ratio was estimated to be $\sim 1.25$. This indicates an average decrease $\kappa$ of $\sim 25 \pm 4 \%$ for ${ }^{28} \mathrm{Si}_{\mathrm{x}}{ }^{30} \mathrm{Si}_{1-\mathrm{x}} \mathrm{NWs}$ with respect to ${ }^{29} \mathrm{Si} \mathrm{NW}$ around room temperature, close to the value reported in recent theoretical simulations ${ }^{28}$ and within the range extracted from experimental measurements carried out using a different technique. ${ }^{29}$ The methodology used to estimate the uncertainties associated with the ratio of $\kappa$ of any two different sets of NWs is shown in Figure S4(b) and it's associated discussion in section D of the SI.

Likewise, the temperature of the ${ }^{\text {Phase }} 3 \mathrm{C}-\mathrm{p}^{28}{ }^{28} \mathrm{Si}_{\mathrm{x}}{ }^{30} \mathrm{Si}_{1-\mathrm{x}}$ NWs and the ${ }^{\text {Phase }} 9 \mathrm{R}-\mathrm{p}$ ${ }^{28} \mathrm{Si}_{\mathrm{x}}{ }^{30} \mathrm{Si}_{1-\mathrm{x}}$ of individual $\mathrm{p}^{28} \mathrm{Si}_{\mathrm{x}}{ }^{30} \mathrm{Si}_{1-\mathrm{x}} \mathrm{NWs}$ was extracted as a function of the laser power density. The evolution of the average local temperature of the ${ }^{\text {Phase }} 9 \mathrm{R}$ and the ${ }^{\text {Phase }} 3 \mathrm{C}$ within the $\mathrm{p}^{2}{ }^{28} \mathrm{Si}_{\mathrm{x}}{ }^{30} \mathrm{Si}_{1-\mathrm{x}} \mathrm{NWs}$ is shown in Figure 4(b). The effective temperature of a single NW was then calculated by taking a weighted average of the local temperature of the individual phases $\left(\mathrm{T}_{3 \mathrm{C}}\right.$ 
and $\mathrm{T}_{9 \mathrm{R}}$ ). The weights were the fractional volume of each phase within a NW, calculated from the integrated area of the Raman signal of the $F_{2 g}$ and $E_{g}$ modes, as extracted from the Voigt line fits after taking into account the difference in the Raman scattering cross-sections of the two Si phases. The method to extract the fractional volume of each phase $\left(V_{3 C}, V_{9 R}\right)$ has been outlined in section $\mathrm{G}$ of the SI. This is a valid approach since the laser absorption is very weak in the probed NWs (i.e., the laser penetration depth at $488 \mathrm{~nm}$ is significantly larger than the NW diameter). The weights were calculated as $\mathrm{w}_{3 \mathrm{C}}=\mathrm{V}_{3 \mathrm{C}} /\left(\mathrm{V}_{3 \mathrm{C}}+\mathrm{V}_{9 \mathrm{R}}\right)$ and $\mathrm{w}_{9 \mathrm{R}}=\mathrm{V}_{9 \mathrm{R}} /\left(\mathrm{V}_{3 \mathrm{C}}+\mathrm{V}_{9 \mathrm{R}}\right)$. The effective temperature of a $\mathrm{p}^{28}{ }^{28} \mathrm{Si}_{\mathrm{x}}{ }^{30} \mathrm{Si}_{1-\mathrm{x}} \mathrm{NW}$ was then calculated as $\mathrm{T}_{3 \mathrm{C}} \mathrm{W}_{3 \mathrm{C}}+\mathrm{T}_{9 \mathrm{R}} \mathrm{W}_{9 \mathrm{R}}$ and the average of such measurements on $\sim 10-15$ different NWs is shown in Figure 4(b). We found that close to room temperature, the rise in temperature of the ${ }^{\text {Phase }} 9 \mathrm{R}-\mathrm{p}-{ }^{28} \mathrm{Si}_{\mathrm{x}}{ }^{30} \mathrm{Si}_{1-\mathrm{x}} \mathrm{NWs}$ with incident laser power is higher by $\sim 18 \pm 3.5 \%$ compared to the ${ }^{\text {Phase }} 3 \mathrm{C}-\mathrm{p}-{ }^{28} \mathrm{Si}_{\mathrm{x}}{ }^{30} \mathrm{Si}_{1-\mathrm{x}} \mathrm{NWs}$. The same trend, that is the ${ }^{\text {Phase }} 9 \mathrm{R}$ heats up by $\sim 18 \%$ more with laser power density compared to the Phase $3 \mathrm{C}$, was also observed for the $\mathrm{p}^{30}{ }^{30} \mathrm{Si} \mathrm{NWs}$ as well, regardless if it is $\mathrm{p}^{30}{ }^{30} \mathrm{Si} \mathrm{NWs} \mathrm{s}_{\mathrm{Tpe} 1}$ or $\mathrm{p}-$ ${ }^{30} \mathrm{Si} \mathrm{NWS}_{\mathrm{Type} 2}$ (not shown here). This was independently verified by estimating the temperature of a single $\mathrm{p}^{30} \mathrm{Si} \mathrm{NWs}_{\mathrm{Type}}$ from the ratio of Stokes to Anti-Stokes intrinsic intensities as shown in Figure S9 and is discussed in section H of the SI. Thus, $\kappa$ of the ${ }^{\text {Phase }} 9 \mathrm{R}$ is lower by $\sim 18 \pm$ $3.5 \%$ close to room temperature relative to the ${ }^{\text {Phase }} 3 \mathrm{C}$ for the same isotopic composition between the two phases within the same NW. The reason for this could be a difference between the two phases in phonon density of states, specific heat, phonon velocity or a combination of these factors. To evaluate the effective temperature of the $\mathrm{p}^{30}{ }^{30} \mathrm{Si} \mathrm{NWs} \mathrm{Nype}_{\text {, }}$, the contribution of the $\mathrm{A}_{1 \mathrm{~g}}$ mode of ${ }^{\text {Phase }} 9 \mathrm{R}$ was completely neglected since it is smaller by more than an order of magnitude compared to both the $E_{g}$ and $F_{2 g}$ modes. Thus, only the shift and the integrated area of the $E_{g}$ 
mode was considered while evaluating $\mathrm{T}_{9 \mathrm{R}}$ and $\mathrm{A}_{9 \mathrm{R}}$, respectively. The shift and the integrated area of the peak at high wavenumbers is entirely attributed to the $\mathrm{F}_{2 \mathrm{~g}}$ mode of ${ }^{\text {Phase }} 3 \mathrm{C}$.

It is noteworthy that the effective temperature of $\mathrm{p}^{30}{ }^{30} \mathrm{Si} \mathrm{NWs} \mathrm{s}_{\mathrm{Typ} 2}$ is found to rise faster as compared to the $\mathrm{p}^{30}{ }^{30} \mathrm{Si} \mathrm{NWs} \mathrm{s}_{\text {Type1. }}$. For $\mathrm{p}^{-}{ }^{30} \mathrm{Si} \mathrm{NWS}_{\mathrm{Type}}$, the effective NW temperature follows the temperature evolution of ${ }^{\text {Phase }} 9 \mathrm{R}$ more closely, while for $\mathrm{p}^{30} \mathrm{SiNW \textrm {N } _ { \text { Type } }}$ it follows the temperature evolution of the ${ }^{\text {Phase }} 3 \mathrm{C}$ phase more closely. The effective temperature evolution for the two types of $\mathrm{p}^{30} \mathrm{Si} \mathrm{NW}$ as a function of laser power density is shown in Figure 4(c). Figure 4(d) compares the temperature evolution for $\mathrm{p}^{30}{ }^{30} \mathrm{Si} \mathrm{NWs} \mathrm{s}_{\text {Type1 }}$ and $\mathrm{p}-{ }^{30} \mathrm{Si} \mathrm{NW} \mathrm{s}_{\text {Type2 }}$ relative to ${ }^{29} \mathrm{Si}$ NWs around room temperature (the linear regime). Note that both ${ }^{29} \mathrm{Si}$ NWs and p${ }^{30} \mathrm{Si} \mathrm{NWs}$ are isotopically pure (hence no phonon scattering from mass-disorder), possess similar morphology (hence similar rate of phonon surface scattering). It can be seen from the respective linear fits that the $\kappa$ of $\mathrm{p}^{-30} \mathrm{Si} \mathrm{NWs}$ Type1 is reduced by $\sim 6 \pm 3.2 \%$ compared to that of ${ }^{29} \mathrm{Si} \mathrm{NWs}$ close to room temperature. On the other hand, $\mathrm{p}^{30}{ }^{30} \mathrm{Si} \mathrm{NWs}_{\mathrm{Type} 2}$ shows a $\kappa$ reduction of $\sim 14 \pm$ $3.8 \%$ relative to ${ }^{29} \mathrm{Si}$ NWs, close to the theoretical calculations reported for ${ }^{\mathrm{Nat}} \mathrm{Si} \mathrm{NWs}$ and ${ }^{\text {Nat }}$ Si NWs with $9 \mathrm{R}$ polytypes. ${ }^{31}$ This also shows that the degree of polytypism is an important factor in determining the net $\kappa$ reduction. The reason for this might be twofold. First, the higher volume of the ${ }^{\text {Phase }} 9 \mathrm{R}$ in the $\mathrm{p}^{30}{ }^{30} \mathrm{Si} \mathrm{NW}_{\mathrm{T}}$ Type2 means that there are more lamellar sections low $\kappa$

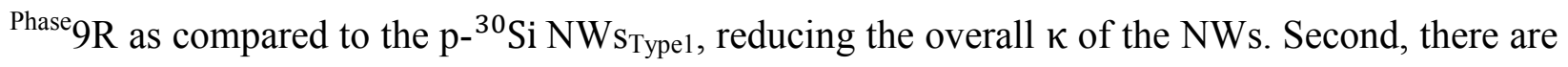
more $3 \mathrm{C} / 9 \mathrm{R}$ interfaces within the $\mathrm{p}^{30} \mathrm{Si} \mathrm{NWs_{ \text {Type2 } }}$ relative to the $\mathrm{p}-{ }^{30} \mathrm{Si} \mathrm{NWs} \mathrm{s}_{\text {Type } 1}$, leading to more interfacial phonon scattering. These interface effects add to the expected difference in phonon properties between $3 \mathrm{C}$ and $9 \mathrm{R}$ phases. Next, the effective temperature evolution of the $\mathrm{p}$ ${ }^{28} \mathrm{Si}_{\mathrm{x}}{ }^{30} \mathrm{Si}_{1-\mathrm{x}} \mathrm{NWs}$ is compared to that of ${ }^{29} \mathrm{Si} \mathrm{NWs}$ in Figure 4(e). The net reduction in $\kappa$ of $\mathrm{p}-$ 
${ }^{28} \mathrm{Si}_{\mathrm{x}}{ }^{30} \mathrm{Si}_{1-\mathrm{x}} \mathrm{NW}$ s relative to ${ }^{29} \mathrm{Si} \mathrm{NWs}$ was found to be $\sim 33 \pm 4.2 \%$, around room temperature. We already stated that $\kappa$ of ${ }^{28} \mathrm{Si}_{\mathrm{x}}{ }^{30} \mathrm{Si}_{1-\mathrm{x}} \mathrm{NWs}$ is reduced by $\sim 25 \%$ relative to that of ${ }^{29} \mathrm{Si} \mathrm{NWs}$. Also note that all $\mathrm{p}^{28} \mathrm{Si}_{\mathrm{x}}{ }^{30} \mathrm{Si}_{1-\mathrm{x}} \mathrm{NWs}$ measured here have $\mathrm{Vol}_{\mathrm{Phase}_{3 \mathrm{C}}}>\mathrm{Vol}_{\mathrm{Phase}_{9 \mathrm{R}}}$. For such NWs, the presence of the polytypes causes an additional lowering of $\kappa$ down to $\sim 67 \%$ of that of isotopically pure ${ }^{29} \mathrm{Si}$ NWs. The highest reduction in $\kappa$ is obtained in ${ }^{\text {Phase }} 9 \mathrm{R}-\mathrm{p}-{ }^{28} \mathrm{Si}_{\mathrm{x}}{ }^{30} \mathrm{Si}_{1-\mathrm{x}}$ NWs. As Figure 4(f) shows that this reduction is $\sim 41.0 \pm 4.5 \%$, close to room temperature. Note, that this reduction in $\kappa$ of the ${ }^{\text {Phase }} 9 \mathrm{R}$ within the $\mathrm{p}^{28} \mathrm{Si}_{\mathrm{x}}{ }^{30} \mathrm{Si}_{1-\mathrm{x}} \mathrm{NWs}$ is a combined effect of the isotopic disorder, polytypic crystal phase, as well as the presence of 3C/9R homointerfaces within these NWs.

The invariance of the isotope effect with crystal phase on the phonon transport in Si NWs is highlighted in Figure 5(a), where we have compared the temperature evolution of Phase $9 \mathrm{R}-\mathrm{p}$ ${ }^{28} \mathrm{Si}_{\mathrm{x}}{ }^{30} \mathrm{Si}_{1-\mathrm{x}} \mathrm{NWs}$ to that of ${ }^{\text {Phase }} 9 \mathrm{R}-\mathrm{p}-{ }^{30} \mathrm{Si} \mathrm{NWs}$ Type1. The plot essentially compares the massdisorder effect for rhombohedral (9R) Si phase. The mass disorder-induced reduction in $\kappa$ is about $\sim 26.5 \pm 4.0 \%$ for the ${ }^{\text {Phase }} 9 \mathrm{R}$, within the uncertainty range of the reduction observed for diamond cubic (3C) Si, shown in Figure 4(a). The reason for this is not too difficult to understand. Kelemens provided a theoretical understanding of the rate of phonon scattering from mass-disorder in a crystal where atoms of mass $\mathrm{m}$ are replaced by isotopes of mass $\mathrm{m}+\Delta \mathrm{m}:^{32}$

$$
\tau_{\text {isotope }}^{-1}=\frac{x(1-x) v V_{0}}{4 \pi \lambda^{4}}\left(\frac{\Delta \mathrm{m}}{\mathrm{m}}\right)^{2}
$$

where $v$ is the phonon velocity, $\lambda$ is the phonon wavelength, $x$ is the fractional composition of the host isotope, and $\mathrm{V}_{0}$ is the volume per atom. Hence, we can expect a difference in $\tau_{\text {isotope }}^{-1}$ between ${ }^{\text {Phase }} 3 \mathrm{C}$ and ${ }^{\text {Phase }} 9 \mathrm{R}$ of similar isotopic compositions because of the possible 
differences in $v$ and/or $\lambda$ between the two phases. But, when comparing between the ${ }^{\text {Phase } 9 \mathrm{R} \text { of }}$ isotopically pure and isotopically mixed NWs, the difference in $\tau_{\text {isotope }}^{-1}$ once again boils down to the second-order moment of mass fluctuation given by $x(1-x)(\Delta \mathrm{m} / \mathrm{m})^{2}$. Since the secondorder moment of mass fluctuations are similar for ${ }^{28} \mathrm{Si}_{\mathrm{x}}{ }^{30} \mathrm{Si}_{1-\mathrm{x}} \mathrm{NWs}$ and $\mathrm{p}-{ }^{28} \mathrm{Si}_{\mathrm{x}}{ }^{30} \mathrm{Si}_{1-\mathrm{x}} \mathrm{NWs}$, the mass disorder-induced reduction in $\kappa$ remains the same for ${ }^{\text {Phase }} 9 \mathrm{R}$.

In summary, we have synthesized isotopically controlled and phase-engineered Si NWs using metal-catalyzed VLS process using enriched precursors. HAADF-STEM analysis showed lamellar sections of 9R crystal phase to be present mostly near the core of the NWs in an otherwise 3C crystal structure. The GPA maps indicated that the lattice is primarily relaxed both in the radial and the axial direction of the polytypic NWs. The average biaxial strain computed from the GPA maps was found to be $0.065 \%$, too small to affect the identification of polytypes which was subsequently done based on Raman peak positions of the $E_{g(2 g)}$ mode of the polytype. Most of the $\mathrm{p}^{28} \mathrm{Si}_{\mathrm{x}}{ }^{30} \mathrm{Si}_{1-\mathrm{x}} \mathrm{NWs}$ showed the signatures of the $9 \mathrm{R}$ polytypes while a few were found to possess the $2 \mathrm{H}$ and $9 \mathrm{R}+2 \mathrm{H}$ polytypes. Out of all the $\mathrm{p}^{-{ }^{28}} \mathrm{Si}_{\mathrm{x}}{ }^{30} \mathrm{Si}_{1-\mathrm{x}} \mathrm{NWs}$ investigated in this work, the Raman signal from the ${ }^{\text {Phase }} 9 \mathrm{R}$ of the $\mathrm{p}^{28} \mathrm{Si}_{\mathrm{x}}{ }^{30} \mathrm{Si}_{1-\mathrm{x}} \mathrm{NWs}$ was always found to be weaker compared to that from the ${ }^{\text {Phase }} 3 \mathrm{C}$. The Raman signal from the $\mathrm{p}-{ }^{30} \mathrm{Si}$ NWs was different in this aspect. The phonon transport measurements were conducted using Raman nanothermometry on the most abundant of polytypic NWs in addition to the isotopically pure ${ }^{29} \mathrm{Si}$ NWs and isotopically mixed ${ }^{28} \mathrm{Si}_{\mathrm{x}}{ }^{30} \mathrm{Si}_{1-\mathrm{x}} \mathrm{NWs}$. The results of these measurements are summarized in Figure 5(b) highlighting the average decrease in $\kappa$ of different NWs and crystal phases relative to the diamond-cubic isotopically pure ${ }^{29} \mathrm{Si} \mathrm{NWs}$. As for a reference, simulations showed the room temperature $\kappa$ of isotopically pure Si NWs of $10 \mathrm{~nm}$ diameter to be $\sim 18$ $\mathrm{W} / \mathrm{mK} .{ }^{28} \kappa$ of ${ }^{28} \mathrm{Si}_{\mathrm{x}}{ }^{30} \mathrm{Si}_{1-\mathrm{x}} \mathrm{NWs}$ is reduced by $\sim 25 \%$ while that of the $\mathrm{p}^{28} \mathrm{Si}_{\mathrm{x}}{ }^{30} \mathrm{Si}_{1-\mathrm{x}} \mathrm{NWs}$ is 


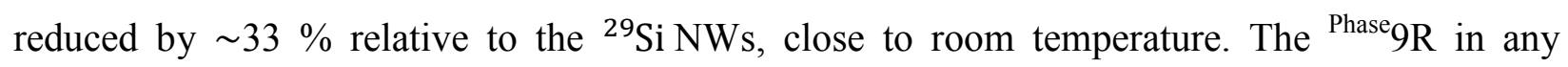
polytypic NW is found to have its $\kappa$ reduced by $\sim 18 \%$ relative to its ${ }^{\text {Phase }} 3 \mathrm{C}$, close to room temperature. The average temperature evolution of a polytypic NW was estimated by taking a weighted average of the temperature evolution of each phase. $\kappa$ of the $p-{ }^{30} \mathrm{Si} \mathrm{NW} \mathrm{s}_{\text {Type } 1}$ is reduced by $\sim 6 \%$ while that of the $\mathrm{p}^{30}{ }^{30} \mathrm{Si} \mathrm{NWs}$ Type2 is reduced by $\sim 14 \%$ relative to the ${ }^{29} \mathrm{Si} \mathrm{NWs}$, close to room temperature. The degree of polytypism is therefore found to play an important role in determining the effective $\kappa$ of a polytypic NW. The mass-disorder induced reduction in $\kappa$ was found to be insensitive to the crystal phase. Our work presented here is the first study that elucidates the combined effect of the mass-disorder and crystal phase on phonon transport in nanoscale systems. To our knowledge, no such study exists even for bulk crystals or thin films. This capacity to control the lattice thermal by isotope and crystal phase engineering lays the groundwork to elucidate the fundamentals of nanoscale thermal transport and its implications for nanoscale heat management and thermoelectrics.

\section{Acknowledgements}

OM acknowledges support from NSERC-Canada (Discovery Grants and Strategic Partnership Grants), Canada Foundation for Innovation, MRIF Québec (Coopération Québec-Catalogne), Mitacs, and Canada Research Chair. JA acknowledge funding from Generalitat de Catalunya 2014 SGR 1638 and the Spanish MINECO coordinated projects VALPEC and ANAPHASE (ENE2017-85087-C3-3-R). ICN2 acknowledges support from the Severo Ochoa Programme (MINECO, Grant no. SEV-2013-0295) and is funded by the CERCA Programme / Generalitat de Catalunya. The HAADF-STEM microscopy was conducted in the Laboratorio de Microscopias Avanzadas at the Instituto de Nanociencia de Aragon-Universidad de Zaragoza. JA and MdlM thank them for offering access to their instruments and expertise.

\section{ASSOCIATED CONTENT}

\section{Supporting Information}

Additional information including experimental details, additional figures, and additional references.

\section{AUTHOR INFORMATION}




\author{
Corresponding author \\ *Email: samik.mukherjee@polymtl.ca \\ *Email: oussama.moutanabbir@polymtl.ca
}

\begin{abstract}
Present affiliations
' Shamoon College of Engineering, Bialik/Basel St., Beer-Sheva 84100, Israel

Instituto de Microscopía Electrónica y Materiales, Departamento de Ciencia de los Materiales e I. M. y Q. I, Facultad de Ciencias, Universidad de Cádiz, 11510, Puerto Real, Spain References
\end{abstract}

(1) D.G. Cahill, P.V. Braun, G. Chen, D.R. Clarke, S.H. Fan, K.E. Goodson, P. Keblinski, W.P. King, G.D. Mahan, A. Majumdar, H.J. Maris, S.R. Phillpot, E. Pop and L.Shi, Appl. Phys. Rev. 2014, 1, 011305.

(2) Chen, R.; Hochbaum, A. I.; Murphy, P.; Moore, J.; Yang, P.; Majumdar, A. Phys. Rev. Lett. 2008, 101 (10), 105501.

(3) Adu, K.; Gutiérrez, H.; Kim, U.; Eklund, P. Phys. Rev. B 2006, 73 (15).

(4) Markussen, T.; Jauho, A.-P.; Brandbyge, M. Phys. Rev. B 2009, 79 (3), 35415.

(5) Lee, E. K.; Yin, L.; Lee, Y.; Lee, J. W.; Lee, S. J.; Lee, J.; Cha, S. N.; Whang, D.; Hwang, G. S.; Hippalgaonkar, K.; Majumdar, A.; Yu, C.; Choi, B. L.; Kim, J. M.; Kim, K. Nano Lett. 2012, 12 (6), 2918-2923.

(6) Hochbaum, A. I.; Chen, R.; Delgado, R. D.; Liang, W.; Garnett, E. C.; Najarian, M.; Majumdar, A.; Yang, P. Nature 2008, 451 (7175), 163-167.

(7) Li, D.; Wu, Y.; Kim, P.; Shi, L.; Yang, P.; Majumdar, A. Appl. Phys. Lett. 2003, 83 (14), 2934.

(8) Boukai, A. I.; Bunimovich, Y.; Tahir-Kheli, J.; Yu, J. K.; Goddard 3rd, W. A.; Heath, J. R. Nature 2008, 451 (7175), 168-171.

(9) Li, D.; Wu, Y.; Fan, R.; Yang, P.; Majumdar, A. Appl. Phys. Lett. 2003, 83 (15), 31863188.

(10) Markussen, T.; Jauho, A.-P.; Brandbyge, M. Phys. Rev. Lett. 2009, 103 (5), 55502.

(11) Sansoz, F. Nano Lett. 2011, 11 (12), 5378-5382.

(12) Cartoixa, X.; Colombo, L.; Rurali, R. Nano Lett. 2015, 15 (12), 8255-8259.

(13) Mukherjee, S.; Givan, U.; Senz, S.; Bergeron, A.; Francoeur, S.; de la Mata, M.; Arbiol, J.; Sekiguchi, T.; Itoh, K. M.; Isheim, D.; Seidman, D. N.; Moutanabbir, O. Nano Lett. 2015, 15 (6), 3885-3893.

(14) Hÿtch, M. J.; Snoeck, E.; Kilaas, R. Ultramicroscopy 1998, 74 (3), 131-146.

(15) de la Mata, M.; Magén, C.; Caroff, P.; Arbiol, J. Nano Lett. 2014, 14 (11), 6614-6620. 
(16) Algra, R. E.; Verheijen, M. A.; Borgström, M. T.; Feiner, L.-F.; Immink, G.; van Enckevort, W. J. P.; Vlieg, E.; Bakkers, E. P. A. M. Nature 2008, 456 (7220), 369-372.

(17) Caroff, P.; Dick, K. A.; Johansson, J.; Messing, M. E.; Deppert, K.; Samuelson, L. Nat. Nanotechnol. 2009, 4 (1), 50-55.

(18) Forrest M. Davidson, I.; Doh C. Lee; Dayne D. Fanfair, A.; Korgel, B. A. J.Phys. Chem.C 2007, 111 (7), 2929-2935.

(19) Lopez, F. J.; Hemesath, E. R.; Lauhon, L. J. Nano Lett. 2009, 9 (7), 2774-2779.

(20) Lopez, F. J.; Givan, U.; Connell, J. G.; Lauhon, L. J. ACS Nano 2011, 5 (11), 8958-8966.

(21) Arbiol, J.; Kalache, B.; Cabarrocas, P. R. I.; Morante, J. R.; Morral, A. F. I. Nanotechnology 2007, 18 (30), 305606.

(22) Arbiol, J.; Fontcuberta i Morral, A.; Estradé, S.; Peiró, F.; Kalache, B.; Roca i Cabarrocas, P.; Morante, J. R. J. Appl. Phys. 2008, 104 (6), 64312.

(23) Jeon, N.; Dayeh, S. A.; Lauhon, L. J. Nano Lett. 2013, 13 (8), 3947-3952.

(24) Tarun, A.; Hayazawa, N.; Ishitobi, H.; Kawata, S.; Reiche, M.; Moutanabbir, O. Nano Lett. 2011, 11 (11), 4780-4788.

(25) Chen, J.; Conache, G.; Pistol, M.-E.; Gray, S. M.; Borgström, M. T.; Xu, H.; Xu, H. Q.; Samuelson, L.; Håkanson, U. Nano Lett. 2010, 10 (4), 1280-1286.

(26) Wong, L. H.; Wong, C. C.; Liu, J. P.; Sohn, D. K.; Chan, L.; Hsia, L. C.; Zang, H.; Ni, Z. H.; Shen, Z. X. Jpn. J. Appl. Phys. 2005, 44 (11), 7922-7924.

(27) Balkanski, M.; Wallis, R.; Haro, E. Phys. Rev. B 1983, 28 (4), 1928-1934.

(28) Royo, M.; Rurali, R. Phys. Chem. Chem. Phys. 2016, 18 (37), 26262-26267.

(29) Swinkels, M. Y. Nanoscale thermal transport, Ph.D. Dissertation, Eindhoven Technische Universiteit, Eindhoven, The Neatherlands, 2017.

(30) Markussen, T.; Jauho, A.-P.; Brandbyge, M. Nano Lett. 2008, 8 (11), 3771-3775.

(31) Zhan, H. F.; Zhang, Y. Y.; Bell, J. M.; Gu, Y. T. J. Phys. D. Appl. Phys. 2014, 47 (1), 15303.

(32) Klemens, P. G. In Proceedings of the Physical Society. Section A; London, 1955; Vol. 68, pp 1113-1128. 
Table 1: Isotopic composition, morphology, crystal phase, and growth conditions of various Si NWs investigated in this work The Si(111) substrates underwent degreasing, dip in 2\% HF for 2 min for native oxide removal, and rinsing in de-ionized water before being put into the UHV chamber.

\begin{tabular}{|c|c|c|c|}
\hline Si NW Type & Morphology & Crystal Phase & $\begin{array}{c}\text { Growth Condition } \\
\end{array}$ \\
\hline $\mathrm{p}^{-28} \mathrm{Si}_{\mathrm{x}}{ }^{30} \mathrm{Si}_{1-\mathrm{x}}$ & $\begin{array}{c}50 \pm 5 \% \text { kink } \\
\text { along }\langle 121\rangle, 50- \\
100 \mathrm{~nm} \text { from the } \\
\text { base } \\
\mathrm{d} \sim 30-60 \mathrm{~nm} \\
\mathrm{~L} \sim 10 \pm 4 \mu \mathrm{m} \\
\mathrm{d} \text { (Diameter) } \\
\text { L (Length) }\end{array}$ & Polytypic & 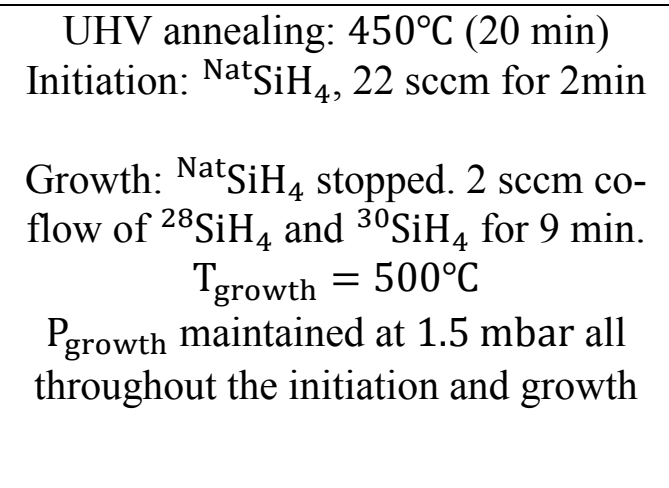 \\
\hline $\mathrm{p}-{ }^{30} \mathrm{Si}$ & $\begin{array}{l}75 \pm 5 \% \text { kink } \\
\text { along }\langle 121\rangle, 50- \\
100 \mathrm{~nm} \text { from the } \\
\quad \text { base } \\
\mathrm{d} \sim 30-60 \mathrm{~nm} \\
\mathrm{~L} \sim 10 \pm 4 \mu \mathrm{m}\end{array}$ & Polytypic & 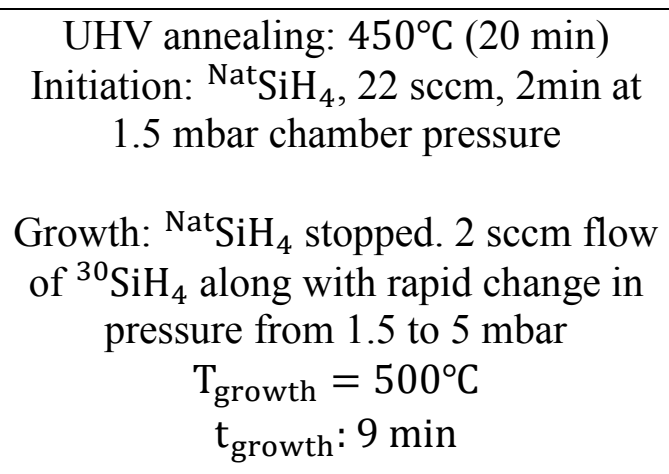 \\
\hline${ }^{28} \mathrm{Si}_{\mathrm{x}}{ }^{30} \mathrm{Si}_{1-\mathrm{x}}$ & $\begin{array}{l}90 \pm 5 \% \text { straight } \\
\text { but some NWs } \\
\text { kink along } \\
\langle 110\rangle \text { at the } \\
\text { substrate } \\
\text { d } \sim 30-60 \mathrm{~nm} \\
\mathrm{~L} \sim 8 \pm 2 \mu \mathrm{m}\end{array}$ & $\begin{array}{c}\text { Diamond } \\
\text { Cubic }(3 \mathrm{C})\end{array}$ & $\begin{array}{c}\text { UHV annealing: } 450^{\circ} \mathrm{C}(20 \mathrm{~min}) \\
\text { Growth: } 2 \mathrm{sccm} \text { co-flow of }{ }^{28} \mathrm{SiH}_{4} \text { and } \\
{ }^{30} \mathrm{SiH}_{4} \text { for } 16 \mathrm{~min} \\
\mathrm{~T}_{\text {growth }}=480^{\circ} \mathrm{C} \\
\mathrm{P}_{\text {growth }}=1.5 \mathrm{mbar}\end{array}$ \\
\hline${ }^{29} \mathrm{Si}$ & $\begin{array}{l}90 \pm 5 \% \text { straight } \\
\text { but some NWs } \\
\text { kink along } \\
\langle 110\rangle \text { at the } \\
\text { substrate } \\
\text { d } \sim 30-60 \mathrm{~nm} \\
\mathrm{~L} \sim 7 \pm 2 \mu \mathrm{m}\end{array}$ & $\begin{array}{c}\text { Diamond } \\
\text { Cubic }(3 C)\end{array}$ & $\begin{array}{c}\text { UHV annealing: } 450^{\circ} \mathrm{C}(20 \mathrm{~min}) \\
\text { Growth: } 2 \text { sccm flow of }{ }^{29} \mathrm{SiH}_{4} \text { for } 11 \\
\text { min. } \\
\mathrm{T}_{\text {growth }}=480^{\circ} \mathrm{C} \\
\mathrm{P}_{\text {growth }}=1.5 \mathrm{mbar}\end{array}$ \\
\hline
\end{tabular}


a)

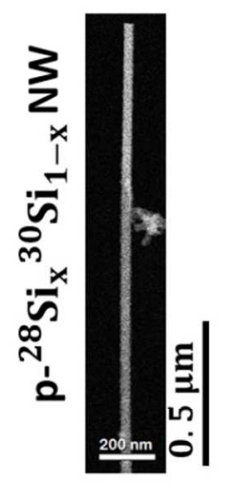

b)

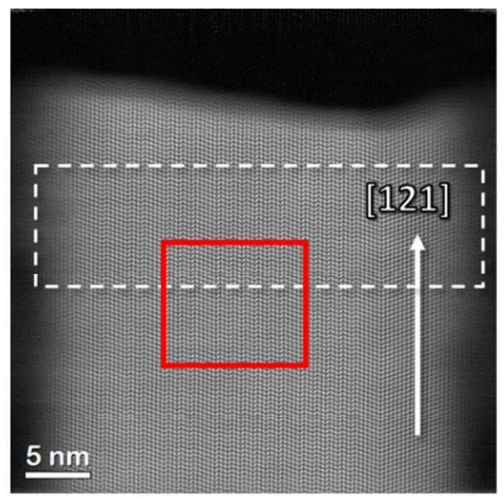

c)

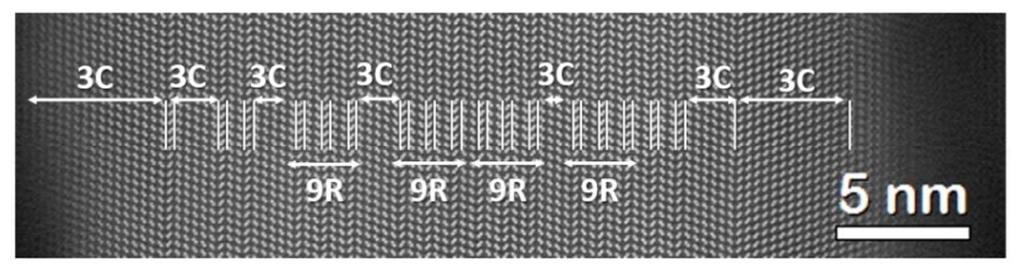

d)

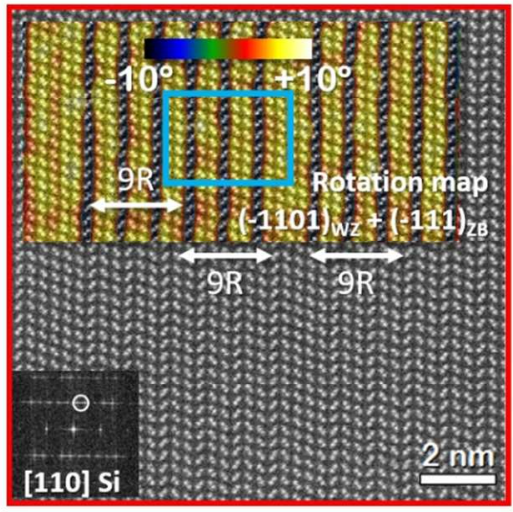

A B A C A C B C B

e)

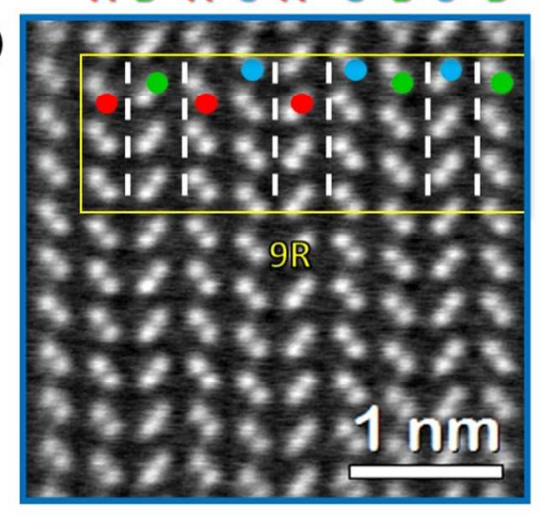

Figure 1: (a)-(e) HAADF-STEM images of a $\mathrm{p}^{28} \mathrm{Si}_{\mathrm{x}}{ }^{30} \mathrm{Si}_{1-\mathrm{x}} \mathrm{NW}$, recorded after the kink, at different levels of magnification. (a) The low magnification image of a $\mathrm{p}^{28} \mathrm{Si}_{\mathrm{x}}{ }^{30} \mathrm{Si}_{1-\mathrm{x}} \mathrm{NW}$, after the kink. (b) High-resolution HAADF-STEM image of the NW showing the growth direction after the kink to be along [121]. (c) High-resolution HAADF-STEM image recorded from the white dotted rectangular box in (b) and shows that the central part of the NW to be polytypic, bounded by the diamond cubic (3C) Si domains. (d) High-resolution HAADF-STEM image recorded from the red square box in (b). The twinned domains are highlighted using false-yellow color. The inset shows the power spectrum (FFT), viewed from the [110] direction and the Bragg's spot marked by the circle was used to generate rotational map. (e) High-resolution HAADF-STEM image recorded at the highest magnification from the blue square box marked in (d) and shows the stacking sequence of $\mathrm{ABACACBCB}$ where each alphabet denotes a bi-layer of atoms. 
a)

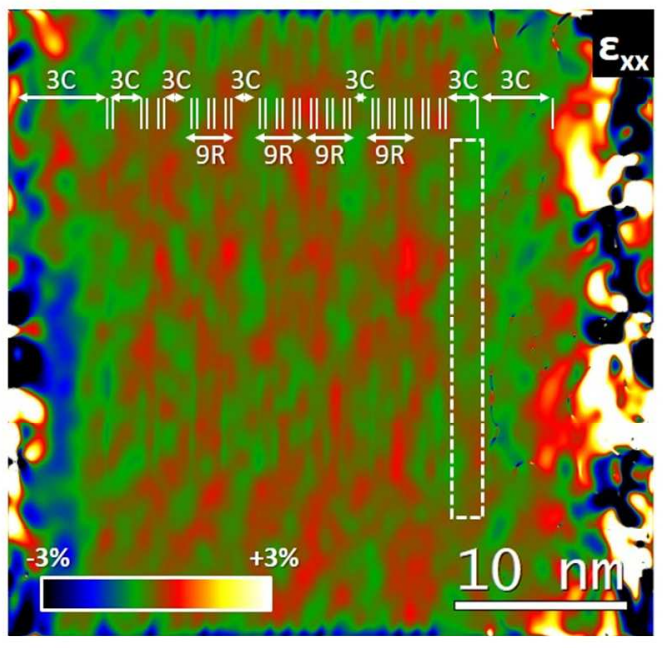

b)

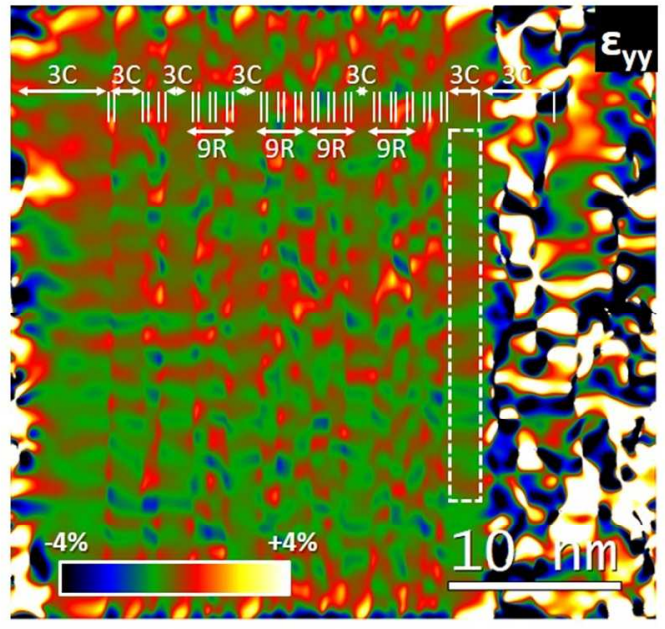

C)
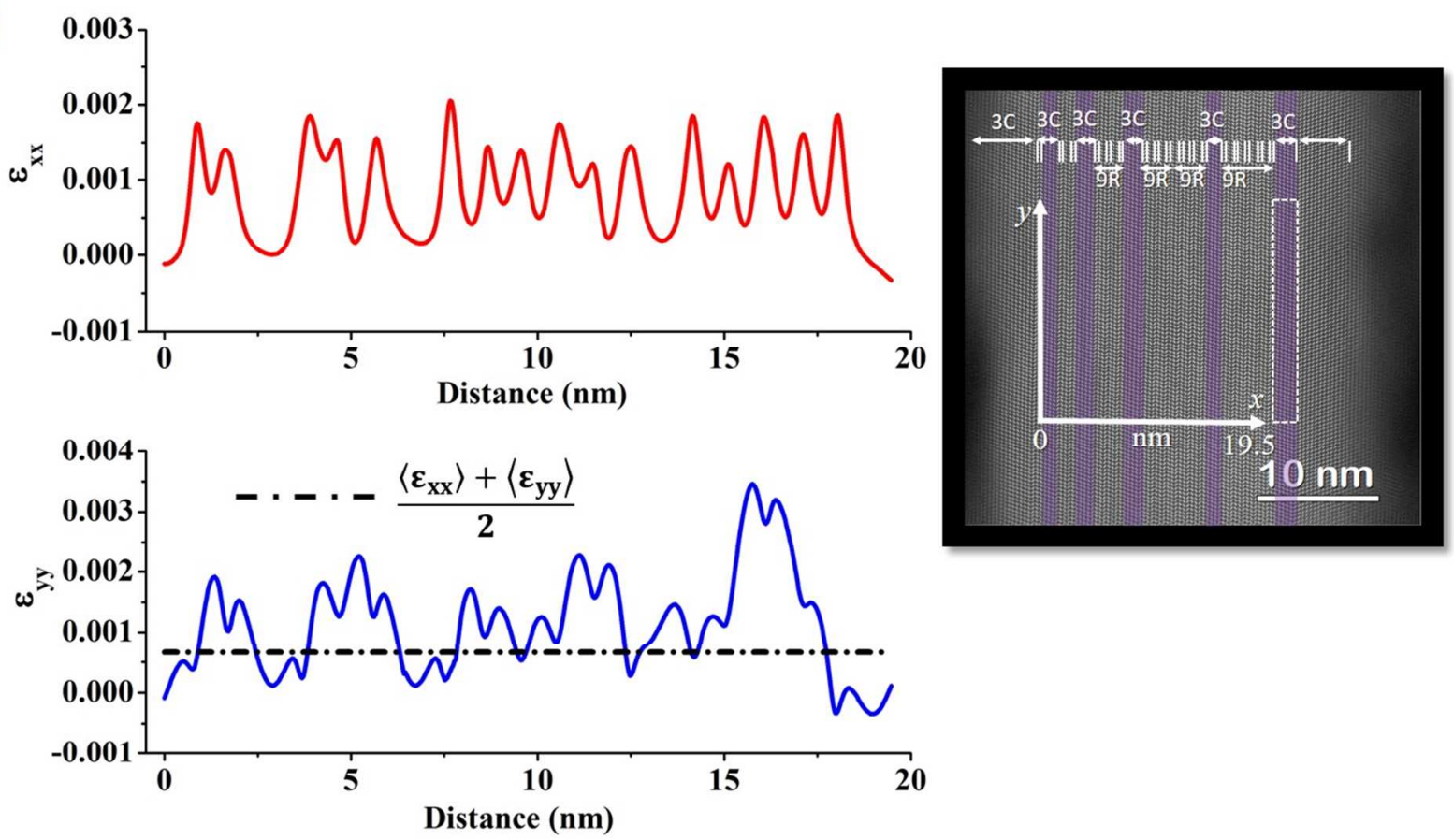

Figure 2: Strain maps (a) $\varepsilon_{x x}$ and (b) $\varepsilon_{y y}$ obtained from the geometric phase analysis on the p${ }^{28} \mathrm{Si}_{\mathrm{x}}{ }^{30} \mathrm{Si}_{1-\mathrm{x}} \mathrm{NW}$ shown in the inset in Figure 2(c). The ' $\mathrm{x}$ ' and ' $\mathrm{y}$ ' axis are marked in the inset. The $3 \mathrm{C}$ region marked by the white rectangular box in (a), (b) was taken as reference for these maps. The $\varepsilon_{x x}$ and $\varepsilon_{y y}$ color bar are shown in the corresponding map. (c) $\varepsilon_{x x}$ (top) and $\varepsilon_{y y}$ (bottom) strain profile over a distance of $19.5 \mathrm{~nm}$, integrated over the length of the white rectangular box. The average biaxial strain is marked by the black dash-dot line in the lower panel. 

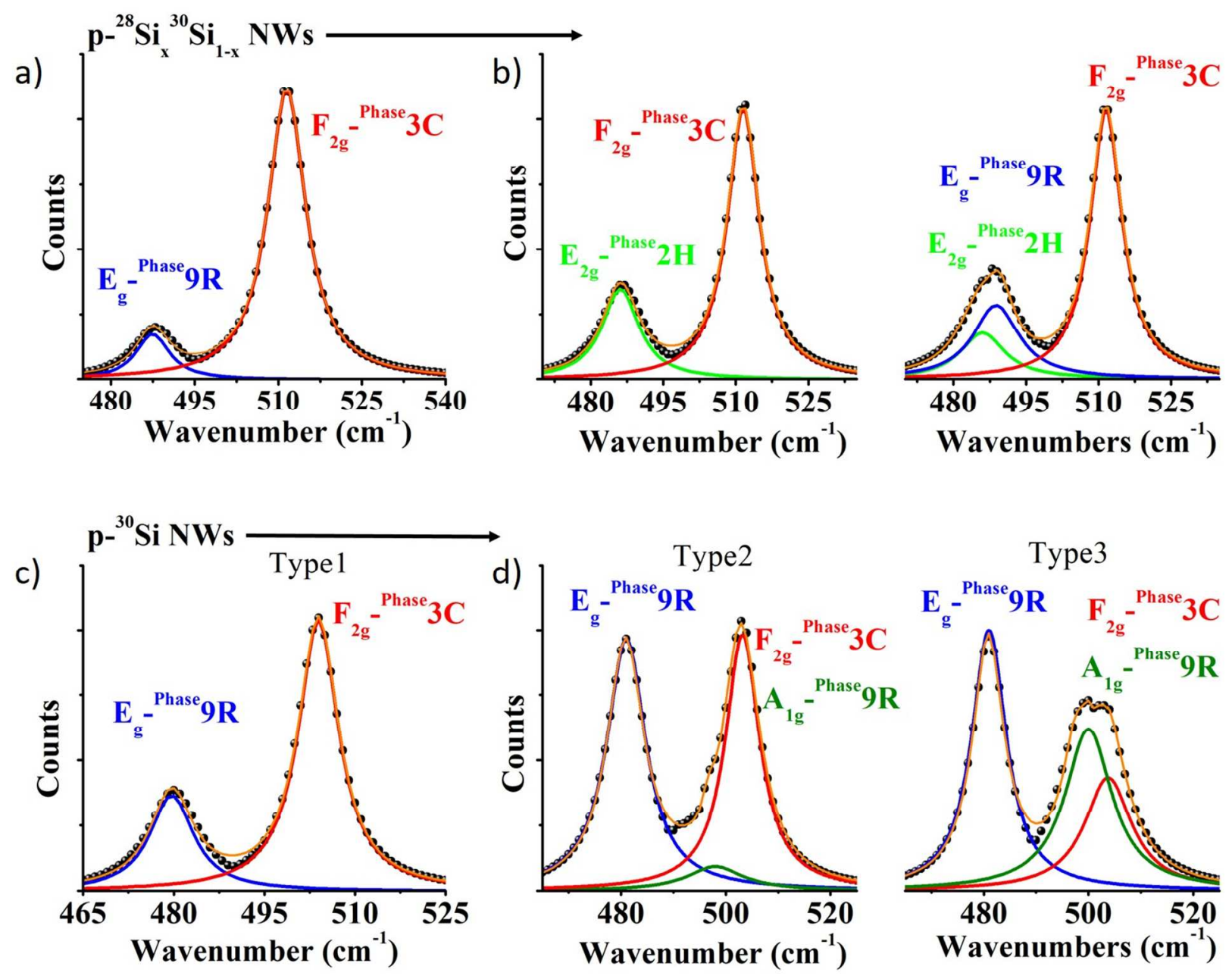

Figure 3: Raman spectra collected from different polytypic NWs dispersed on Au substrate. In all the plots, the baseline corrected and normalized raw data is shown by black circles. The data was fitted with two or three Voigt function(s) depending on whichever gave the best $\mathrm{R}^{2}$ for the cumulative fit. The cumulative fit in all the plots are shown using the orange line. (a) Raman spectra of a single $\mathrm{p}^{28} \mathrm{Si}_{\mathrm{x}}{ }^{30} \mathrm{Si}_{1-\mathrm{x}} \mathrm{NW}$ showing the $\mathrm{E}_{\mathrm{g}}$ and $\mathrm{F}_{2 \mathrm{~g}}$ modes from ${ }^{\text {Phase }} 9 \mathrm{R}$ (blue line) and the ${ }^{\text {Phase }} 3 \mathrm{C}$ (red line), respectively. (b) Left: Raman spectra of a single $\mathrm{p}-{ }^{28} \mathrm{Si}_{\mathrm{x}}{ }^{30} \mathrm{Si}_{1-\mathrm{x}} \mathrm{NW}$ showing the $\mathrm{E}_{2 \mathrm{~g}}$ and $\mathrm{F}_{2 \mathrm{~g}}$ modes from ${ }^{\text {Phase }} 2 \mathrm{H}$ (light green line) and the Phase $3 \mathrm{C}$ (red line), respectively. Right: Raman spectra showing the $\mathrm{E}_{\mathrm{g}}, \mathrm{E}_{2 \mathrm{~g}}$, and $\mathrm{F}_{2 \mathrm{~g}}$ modes showing the presence of both $9 \mathrm{R}$ and $2 \mathrm{H}$ polytypic phases within a $\mathrm{p}^{28} \mathrm{Si}_{\mathrm{x}}{ }^{30} \mathrm{Si}_{1-\mathrm{x}} \mathrm{NW}$. (c) Raman spectra of a single $\mathrm{p}-{ }^{30} \mathrm{Si} \mathrm{NW}_{\text {Type } 1}$ showing the weaker $\mathrm{E}_{\mathrm{g}}$ mode from ${ }^{\text {Phase }} 9 \mathrm{R}$ (blue line) and the stronger $\mathrm{F}_{2 \mathrm{~g}}$ mode from the ${ }^{\text {Phase }} 3 \mathrm{C}$ (red line), (d) Left: Raman spectra of a single $\mathrm{p}-{ }^{30} \mathrm{Si} \mathrm{NW}_{\text {Type2 }}$ showing the $\mathrm{E}_{\mathrm{g}}$ mode from ${ }^{\text {Phase }} 9 \mathrm{R}$ (blue line) and $\mathrm{F}_{2 \mathrm{~g}}$ mode from ${ }^{\text {Phase }} 3 \mathrm{C}$ (red line) to be of equal strength. The weak $\mathrm{A}_{1 \mathrm{~g}}$ mode from the Phase $9 \mathrm{R}$ (green line) is also visible. Right: Raman spectra of a single $\mathrm{p}-{ }^{30} \mathrm{Si} \mathrm{NW}_{\text {Type }}$ showing the $\mathrm{E}_{\mathrm{g}}$ mode from ${ }^{\text {Phase }} 9 \mathrm{R}$ (blue line) to be stronger than the $\mathrm{F}_{2 \mathrm{~g}}$ mode from ${ }^{\text {Phase }} 3 \mathrm{C}$ (red line). The strength of the $A_{1 g}$ mode from the ${ }^{\text {Phase }} 9 \mathrm{R}$ (green line) is stronger than that of the $F_{2 g}$ mode. 
a)

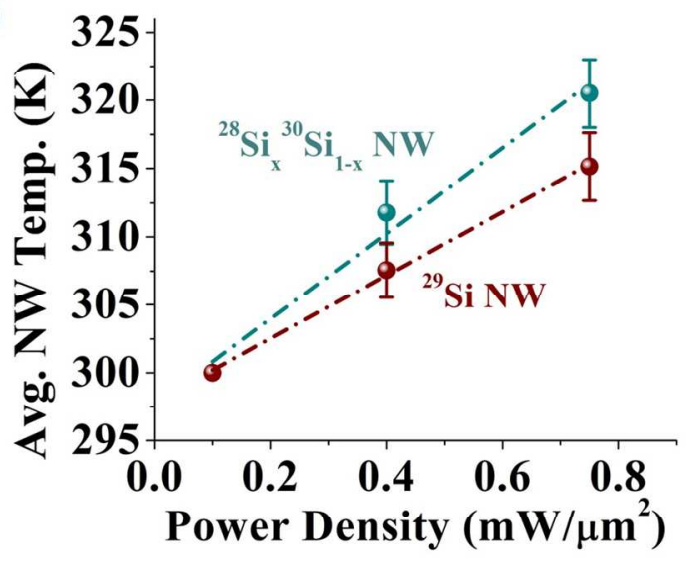

d) Power Density $\left(\mathrm{mW} / \mu \mathrm{m}^{2}\right)$

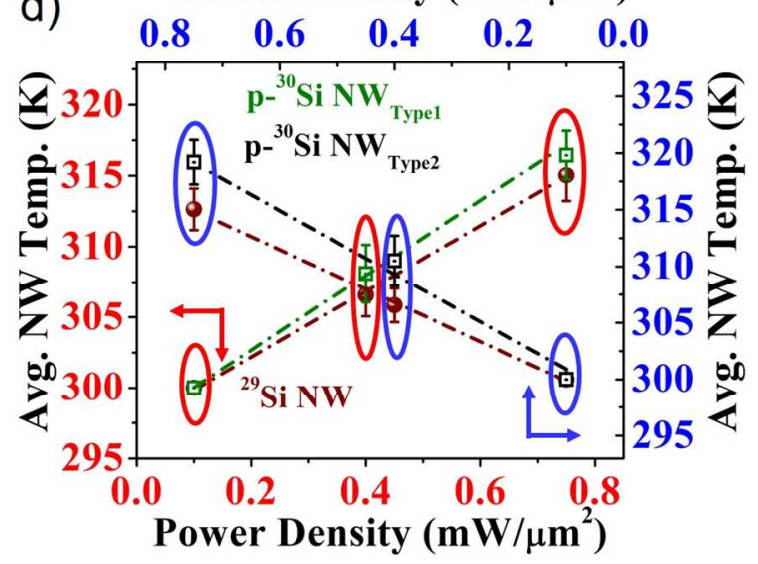

b)

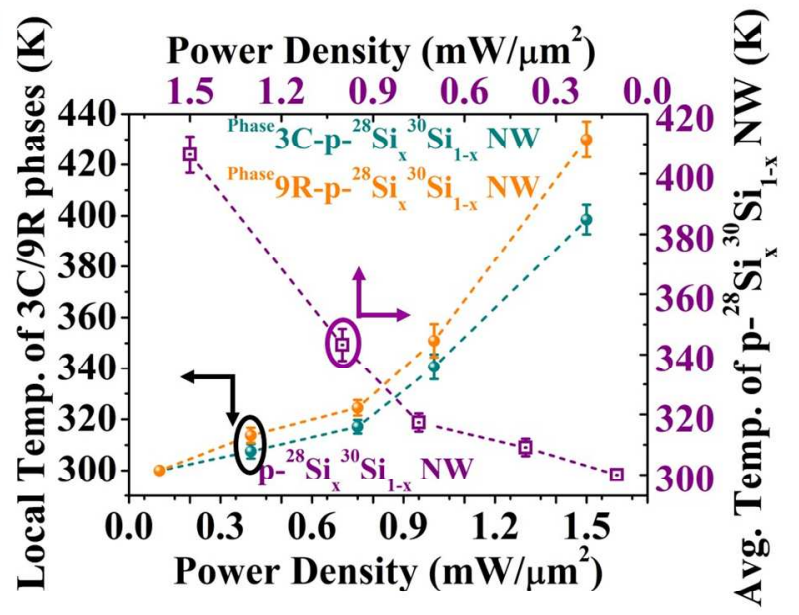

e)

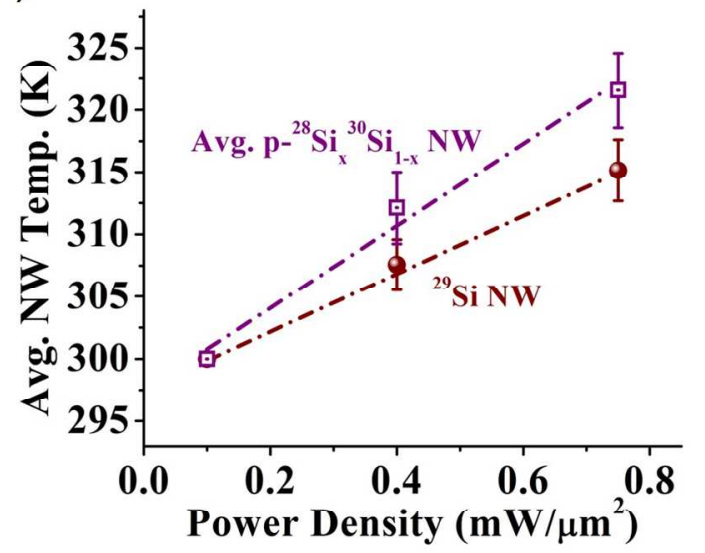

f)

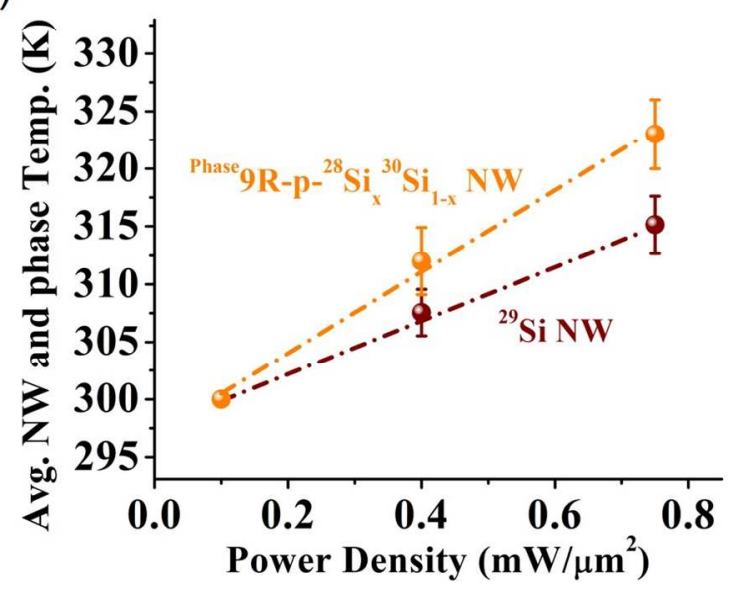

Figure 4: Evolution of the average NW temperature and the local temperature of different crystal phases with incident laser power density. (b)-(c) show the temperature evolution over the 
entire power range $\left(0.1-1.5 \mathrm{~mW} / \mu^{2}\right)$ while (a), (d)-(f) shows the comparisons at only the first three data points (linear regime): $0.1,0.4$, and $0.75 \mathrm{~mW} / \mu \mathrm{m}^{2}$. (a) Evolution of the average local temperature of the ${ }^{28} \mathrm{Si}_{\mathrm{x}}{ }^{30} \mathrm{Si}_{1-\mathrm{x}} \mathrm{NWs}$ (cyan) and ${ }^{30} \mathrm{Si} \mathrm{NWs}$ (brown) with incident laser power density. (b) Evolution of the average local temperature of the ${ }^{\text {Phase }} 9 \mathrm{R}$ (orange) and ${ }^{\text {Phase }} 3 \mathrm{C}$ (cyan) and the effective temperature of the $\mathrm{p}^{2}{ }^{28} \mathrm{Si}_{\mathrm{x}}{ }^{30} \mathrm{Si}_{1-\mathrm{x}} \mathrm{NWs}$ (purple). (c) Evolution of the effective temperature of the $\mathrm{p}^{30} \mathrm{Si} \mathrm{NW}$ Type1 (green) and $\mathrm{p}^{30}{ }^{30} \mathrm{Si} \mathrm{NW}$ Type2 (black). (d) Comparison of the average temperature evolution of the $\mathrm{p}^{30}{ }^{30} \mathrm{Si} \mathrm{NW}$ Type1 (green) and $\mathrm{p}-{ }^{30} \mathrm{Si} \mathrm{NW}$ Type2 (black) with that of ${ }^{29} \mathrm{Si} \mathrm{NW}$ (brown). (e) Comparison of the average temperature evolution of the $\mathrm{p}-{ }^{28} \mathrm{Si}_{\mathrm{x}}{ }^{30} \mathrm{Si}_{1-\mathrm{x}}$ NWs (purple) with that of ${ }^{29} \mathrm{Si} \mathrm{NW}$ (brown). (f) Comparison of the temperature evolution of the ${ }^{\text {Phase }}$ 9R-p- ${ }^{28} \mathrm{Si}_{\mathrm{x}}{ }^{30} \mathrm{Si}_{1-\mathrm{x}} \mathrm{NWs}$ (orange) with that of ${ }^{29} \mathrm{Si} \mathrm{NW}$ (brown). The error bars represent the uncertainties in estimating the average NW temperature. The uncertainties occur due to the finite standard deviation of the average NW temperature over temperature of 10-15 individual NWs. Since the temperature of the individual NWs (and phases) was assumed to be $300 \mathrm{~K}$ at the lowest laser power density (as a boundary condition), the first data point is devoid of any error bars. The first data point of the average temperature in polytypic NW have a small standard deviation since it was calculated using the weighted average technique. Although the individual phases are at the same temperature $(300 \mathrm{~K})$ at the lowest laser power density, the weights are not the same for all the 10-15 individual NWs measured. Nonetheless, the error bar originating from this difference in weights are smaller than the data symbols used. In all the figures, the dashed lines are guide to the eye while the dot-dash-dot lines represent the linear fit to the data. 
2

3

4

5

6

7

8 a)

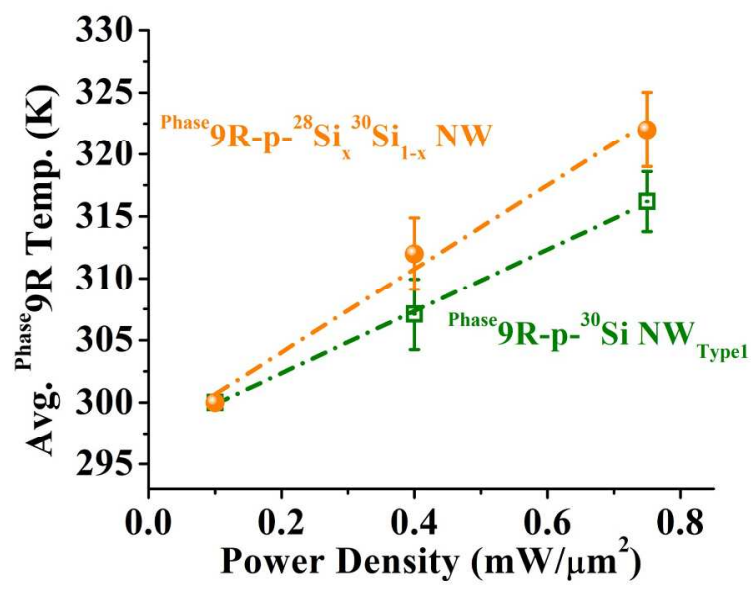

b)

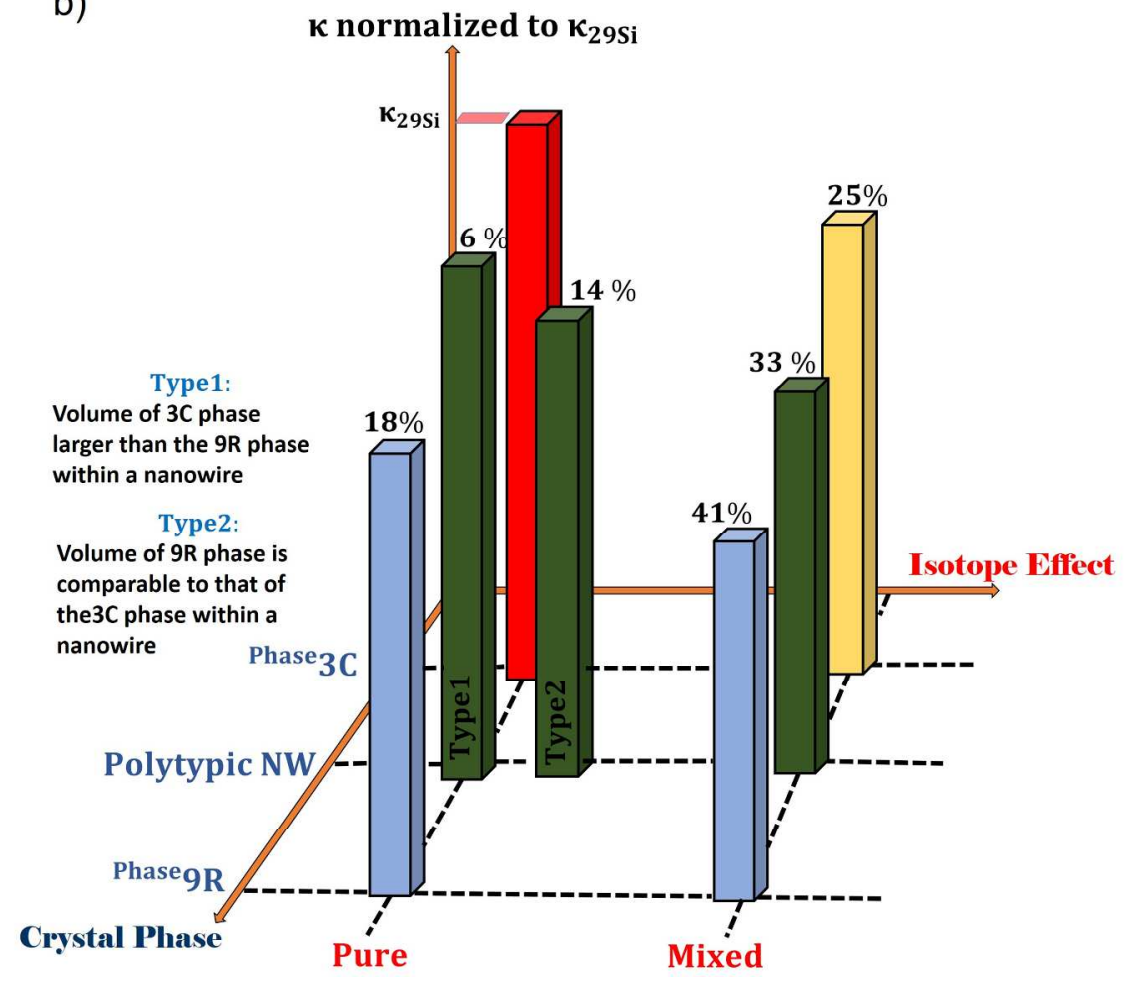

Figure 5: (a) Comparison of the temperature evolution of the ${ }^{\text {Phase }} 9 \mathrm{R}-\mathrm{p}-{ }^{28} \mathrm{Si}_{\mathrm{x}}{ }^{30} \mathrm{Si}_{1-\mathrm{x}} \mathrm{NWs}$ (orange) with that of ${ }^{\text {Phase } 9 R-p-{ }^{30} \mathrm{Si} \mathrm{NW}}$ Type1 (green). The dot-dash-dot lines represent the linear fit to the data. The error bars represent the uncertainties in estimating the average NW temperature. The uncertainties occur due to the finite standard deviation of the average NW temperature over temperature of 10-15 individual NWs (and phases). Since the temperature of the individual NWs (and phases) was assumed to be $300 \mathrm{~K}$ at the lowest laser power density (as a boundary condition), the first data point is devoid of any error bars. (b) Comparison of the lattice thermal conductivity of different phases and NWs relative to that of the ${ }^{29} \mathrm{Si} \mathrm{NWs}$, close to room temperature. 


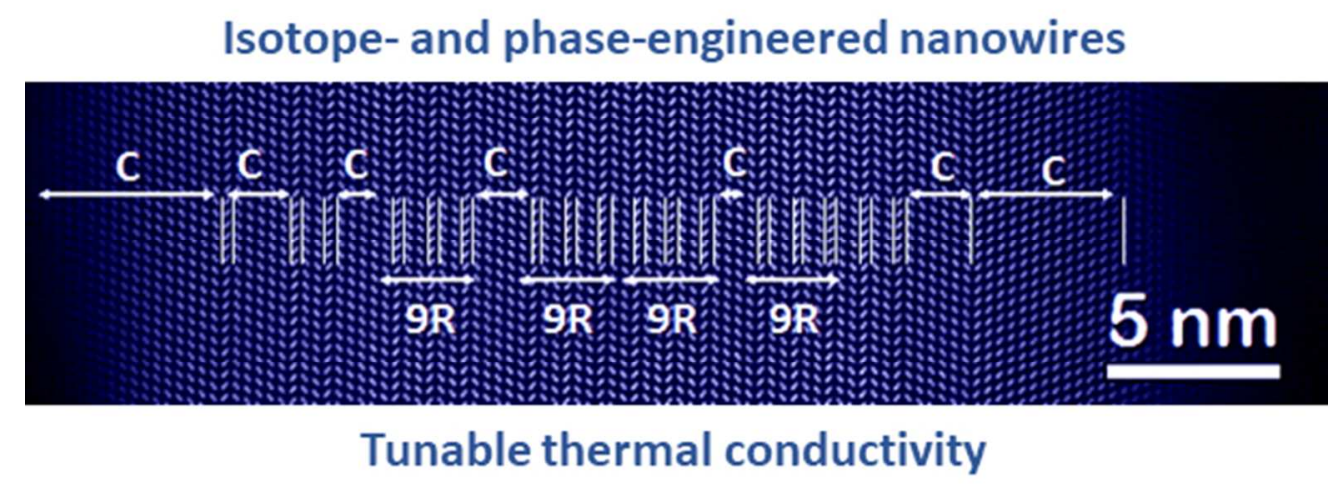

$160 \times 60 \mathrm{~mm}(96 \times 96 \mathrm{DPI})$ 